
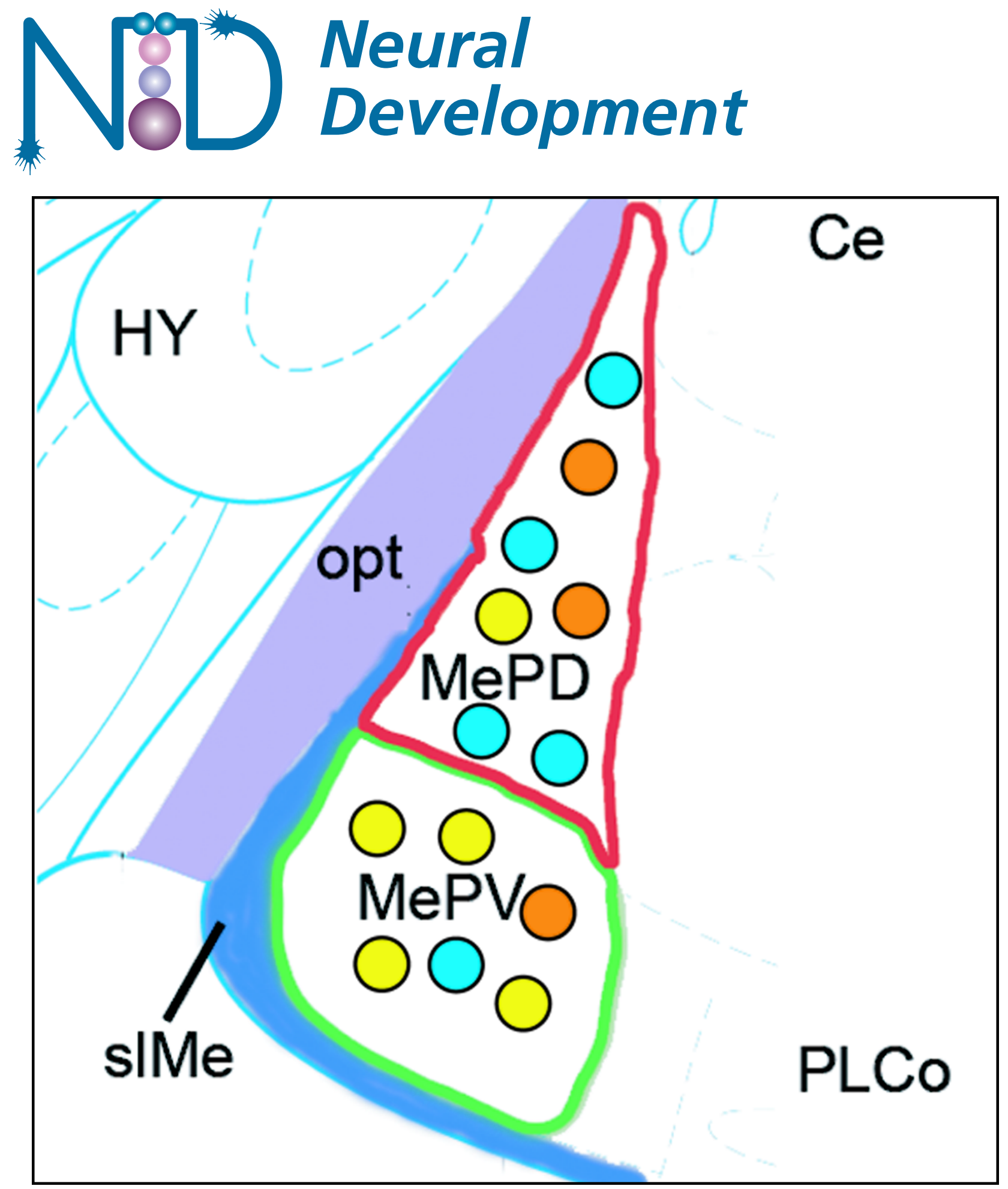

Sonic hedgehog expressing and responding cells generate neuronal diversity in the medial amygdala

Carney et al. 


\title{
Sonic hedgehog expressing and responding cells generate neuronal diversity in the medial amygdala
}

\author{
Rosalind SE Carney11,4, Jean-Marie Mangin', Lindsay Hayes², Kevin Mansfield', Vitor H Sousa33, Gord Fishell3, \\ Robert P Machold³, Sohyun Ahn², Vittorio Gallo' and Joshua G Corbin*1
}

\begin{abstract}
Background: The mammalian amygdala is composed of two primary functional subdivisions, classified according to whether the major output projection of each nucleus is excitatory or inhibitory. The posterior dorsal and ventral subdivisions of the medial amygdala, which primarily contain inhibitory output neurons, modulate specific aspects of innate socio-sexual and aggressive behaviors. However, the development of the neuronal diversity of this complex and important structure remains to be fully elucidated.
\end{abstract}

Results: Using a combination of genetic fate-mapping and loss-of-function analyses, we examined the contribution and function of Sonic hedgehog (Shh)-expressing and Shh-responsive (Nkx2-1+ and Gli $\left.{ }^{+}\right)$neurons in the medial amygdala. Specifically, we found that Shh-and Nkx2-7-lineage cells contribute differentially to the dorsal and ventral subdivisions of the postnatal medial amygdala. These Shh- and Nkx2-1-lineage neurons express overlapping and nonoverlapping inhibitory neuronal markers, such as Calbindin, FoxP2, nNOS and Somatostatin, revealing diverse fate contributions in discrete medial amygdala nuclear subdivisions. Electrophysiological analysis of the Shh-derived neurons additionally reveals an important functional diversity within this lineage in the medial amygdala. Moreover, inducible Gli TreER(T2) temporal fate mapping shows that early-generated progenitors that respond to Shh signaling also contribute to medial amygdala neuronal diversity. Lastly, analysis of Nkx2-1 mutant mice demonstrates a genetic requirement for $\mathrm{Nk} \times 2-1$ in inhibitory neuronal specification in the medial amygdala distinct from the requirement for Nkx2-1 in cerebral cortical development.

Conclusions: Taken together, these data reveal a differential contribution of Shh-expressing and Shh-responding cells to medial amygdala neuronal diversity as well as the function of Nkx2-1 in the development of this important limbic system structure.

\section{Background}

The mammalian amygdala is an aggregation of 11 to 15 nuclei, which as components of the limbic system mediate distinct aspects of emotional and behavioral processing as well as socio-sexual behaviors (reviewed in [1]). The amygdala is considered in terms of two functional subdivisions, classified according to whether the major output projection of each nucleus is excitatory or inhibitory. Based on this classification, the nuclei of the basolateral complex and cortical amygdalar nuclei, which have

* Correspondence: jcorbin@cnmcresearch.org

${ }^{1}$ Center for Neuroscience Research, Children's Research Institute, Children's National Medical Center, Washington, DC 20010, USA

Full list of author information is available at the end of the article an excitatory output, have been hypothesized to be of a pallial origin, whereas the cortical and medial nuclei are broadly considered similar to the striatum as their output projections are primarily inhibitory. Several studies have revealed that, during embryogenesis, the emerging amygdala is generated from several forebrain embryonic domains, including the pallium, pallial-subpallial boundary, medial ganglionic eminence (MGE), preoptic area (POA) and perhaps the diencephalon [2-10].

The medial amygdala (MeA) subnuclei process pheromonal information, and regulate neuroendocrine function and socio-sexual behaviors. Anatomically, the posterior portion of the MeA is divided into dorsal 
(medial posterodorsal nucleus (MePD)) and ventral (medial posteroventral nucleus (MePV)) subdivisions, which via their projections to distinct hypothalamic nuclei regulate reproductive and defensive behaviors, respectively (reviewed in $[1,11]$ ). Although not well-characterized, recent studies have revealed insight into the development of the MeA. In terms of circuit formation, the anatomical segregation of efferent projections that regulate reproductive or defensive behaviors is differentially marked by the LIM-containing homeodomain genes $L h x 6$ and $L h x 9[12,13]$. In the embryonic subpallium, Lhx6 is expressed in tangentially migrating cortical interneurons [14-16], and is a direct transcriptional target of $N k x 2-1$, which is expressed in the embryonic MGE and POA $[17,18]$. In addition, our recent work has revealed that the embryonic telencephalic POA is a major novel source of MeA neurons [3]. Moreover, $N k x 2$-1-lineage cells have been shown to contribute to the anterior MeA, although their neurochemical fate was not determined [5]. Despite this developmental information, the lineages that contribute to the vast inhibitory neuronal diversity in the MeA remain largely unknown.

Based on the expression patterns of the morphogen Sonic hedgehog (Shh) as well as the Shh-responsive genes Nkx2-1 and Gli1 in the embryonic MGE and POA $[19,20]$ and, at later developmental stages (by embryonic day 14.5 (E14.5)), expression of Shh in the MePV [2], we hypothesized that progenitor populations marked by these genes contribute to inhibitory neuronal diversity in the postnatal MeA. In this study, we find that Shh-, Nkx2-1- and Gli1-lineage cells generate inhibitory neuronal diversity in the MePD and MePV in a largely complementary manner. We further reveal a differential functional requirement for $N k x 2-1$ in the development of the MePD compared to the MePV, and find that Shh-lineage cells generate three functionally distinct classes of neurons in the posterior MeA as defined by electrophysiological criteria. Thus, these data provide novel insights into the lineage and genetic mechanisms that generate the amygdala nuclei that mediate socio-sexual behaviors.

\section{Results}

Embryonic expression of Nkx2-1, Shh and Gli1 and recombined cells

Progenitor pools in the embryonic telencephalon are marked by spatio-temporal diversity in gene expression patterns. Expression of these genes is typically down-regulated as cells become post-mitotic. To permanently label these transiently marked populations, we used transgenic mouse lines that express Cre recombinase under transcriptional regulation of Shh, Nkx2-1 and Gli1 [5,21,22]. The developmental expression of these genes has been well-characterized in previous studies. At E11.5 and E13.5, Nkx2-1 is expressed throughout the MGE progeni- tor domains (pMGE 1-5) and the progenitor domains of the dorsal (pPOA1) and ventral (pPOA2) subdivisions of the embryonic POA [19]. In addition, previous studies [5] revealed that $N k \times 2-1$-derived cells, using the same $N k \times 2$ 1-Cre mouse line as in this study, migrate toward the developing amygdala. At E11.5, Shh is expressed in the MGE mantle zone and in the progenitor domains of the POA (pPOA1 and pPOA2) and in a small region of the septum [19,23]. Gli1 is a transcriptional target of Shh and its expression, therefore, is observed near Shh-expressing domains [24-26]. Consequently, at early developmental time points Gli1 mRNA expression is observed in the ventral POA (pPOA2) and the sulcus between the lateral ganglionic eminence (LGE) and the MGE (pLGE4 and pMGE1) [20,27].

As Tau ${ }^{m G F P}$ mice were generated with a nuclear localization signal for LacZ [28], we used X-gal staining to visualize recombined cells. Our short-term recombination analyses at E12.5 revealed waves of putative migrating cells emanating from the ventral telencephalon to the prospective developing amygdaloid region. In the $\mathrm{Sh} h \mathrm{Cre}$; Ta $u^{m G F P}$ line we observed intense $\mathrm{X}$-gal staining in the post-mitotic regions of the MGE, POA and ventral telencephalon (Figure 1A-D). Shh-lineage cells were also observed to a lesser extent in the developing thalamus, cerebral cortex and hippocampus (Figure 1A-D). This result is also consistent with a recent study using the ROSA26 LacZ reporter mouse that showed Shh-lineage cells also in domains of the POA and MGE [29]. As MeA neurons are generated from as early as E10 [3,4], we administered a single dose of tamoxifen (TM) at E9.5 (TM E9.5) in pregnant dams from Gli1CreER(T2); Tau ${ }^{m G F P}$ crosses to label Shh-responder cells $\left(\mathrm{Gli1}^{+}\right)$at approximately E10.5. When analyzed at E12.5, X-gal staining was observed in a number of cells in the post-mitotic region of the MGE and POA (Figure 1E-H), similar to that observed for the ShhCre line. Furthermore, Foxg1 mRNA expression (Figure 1E-H, insets) on adjacent sections showed that the basally located short-term recombined cells in the ShhCre and Gli1CreER(T2) lines were located in the telencephalon as opposed to the diencephalon.

In summary, based on our analyses and previous studies, Shh, Nkx2-1 and Gli1 are spatially and temporally present in progenitor domains known to contribute to the MeA. Therefore, we next focused our analyses on the postnatal characterization of these genetically labeled cell populations.

Nkx2-1- and Shh-lineage cells preferentially accumulate in different subdivisions of the adult posterior MeA

To determine whether Shh-, Nkx2-1- and Gli1-derived cells contribute to the dorsal and ventral subdivisions of the posterior MeA (Figure 2A), we analyzed their distribution patterns at postnatal day 22 (P22). In Nkx2-1-Cre; 


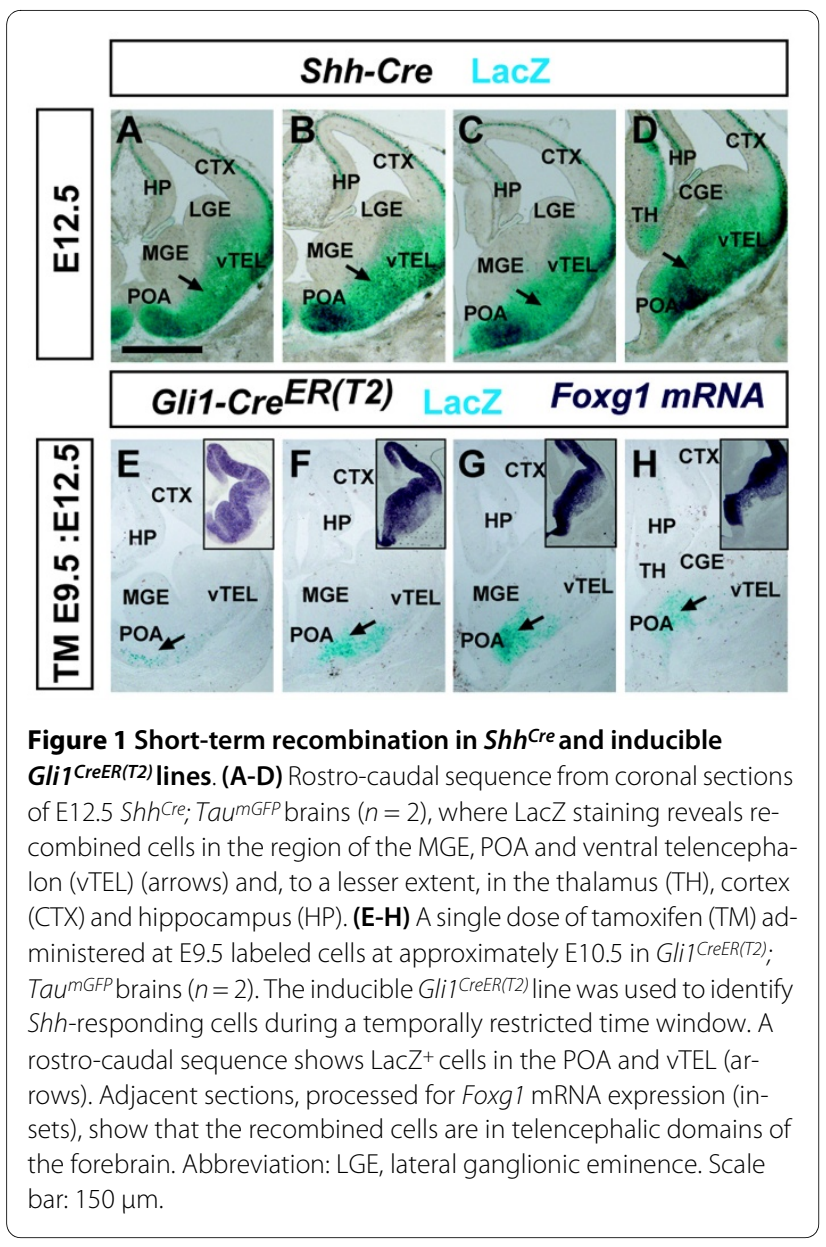

Tau $^{m G F P}$ brains LacZ ${ }^{+}$cells were predominantly located in the MePD (Figure 2B, E, H). In addition, Shh-lineage cells contributed substantially to the posterior MeA (Figure 2C, F, I). Interestingly, this distribution of Shh-lineage cells appeared largely complementary to that of the $N k \times 2-$ 1-lineage population. In contrast to these primarily complementary patterns of recombination, Shh-responding cells (Gli1-derived) labeled at approximately E10.5 (TM E9.5) were distributed between both the MePD and MePV (Figure 2D, G, J).

Taken together, these results show that the dorsal (MePD) and ventral (MePV) subdivisions of the adult posterior MeA can be preferentially populated from $N k \times 2-1$ - and Shh-lineages, respectively. Nkx2-1-lineage cells are predominantly observed in the MePD whereas Shh-lineage cells are mainly observed in the MePV. In addition, we show that Gli1-derived cells contribute to both subdivisions of the posterior MeA.

\section{Characterization of inhibitory neuronal cell types in the posterior MeA}

Neuronal cell diversity in the MeA has not been thoroughly explored. Therefore, we first wanted to characterize the molecular/neurochemical profiles of specific cell types in both the MePD and MePV. We reasoned that this analysis was a necessary prerequisite for subsequent analysis of the fate of Nkx2-1-, Shh- and Gli1-derived populations. To this end, we immunostained P22 wild-type mice with a battery of antibodies against proteins whose expression patterns are well-characterized in other forebrain structures but have not been directly compared to or between the subdivisions of the posterior MeA. As the $\mathrm{MeA}$ is largely composed of GABAergic neurons (reviewed in [1]), expression of Tbr1, which is a marker of excitatory neurons $[30,31]$, was only observed in the ventral-most portion of the MePV, adjacent to the superficial layer of the MeA (Additional file 1A, B). Conversely both the MePD and MePV were highly immunoreactive for the GABA synthesizing enzymes GAD65/67 (Additional file $1 C, D)$. Surprisingly, we found that expression of Parvalbumin and Neuropeptide $\mathrm{Y}$, which are markers of inhibitory neuronal subtypes in the cerebral cortex and striatum, were nearly absent from the posterior MeA (Additional file 1E-H).

Interestingly, other markers showed differential expression patterns between both subdivisions. Calbindin, which labels approximately half of all cerebral cortical inhibitory neurons (reviewed in [32]), was observed scattered throughout the MePV, though as previously noted the distribution of Calbindin ${ }^{+}$cells appeared to be more concentrated near the optic tract (Figure 3A, B) [33]. Immunoreactivity to neuronal nitric oxide synthase (nNOS) labeled many medium-sized cells, which showed strong cytoplasmic staining surrounding an unstained nucleus and immunoreactive neuropil located in the MePV (Figure 3C), although similar to Calbindin, more nNOS $^{+}$cells were observed in the medial part of the MePD, bordering the optic tract (Figure 3D). On the other hand, the expression of the Forkhead box transcription factor FoxP2, which marks a subpopulation of MeA neurons of unknown profiles [34], was highly expressed in both the main body of the MePV (Figure 3E), and the MePD (Figure 3F). We also observed that the interneuron marker Somatostatin (SST), which is expressed in the MeA [35], was found in scattered cells in both subdivisions (Figure 3G, H).

\section{Nkx2-1-, Shh- and Gli1-lineage cells contribute to inhibitory neuronal diversity in the posterior MeA}

Based on the above analysis of inhibitory neuronal distribution in the posterior MeA, we focused our fate analysis on the neuronal subtypes characterized by expression of Calbindin, nNOS, FoxP2, and SST. We performed immunolabeling for these markers in combination with an anti$\beta$-galactosidase ( $\beta$-gal) antibody to visualize nuclear staining in recombined cells from $\mathrm{Nk} \times 2-1-\mathrm{Cre}$, ShhCre and Gli1 ${ }^{C r e E R(T 2) ~(T M ~ E 9.5) ~ b r a i n s ~(F i g u r e s ~} 4$ and 5). This analysis revealed that $69 \%$ of the $\beta$-gal ${ }^{+}$cells in the MePD 


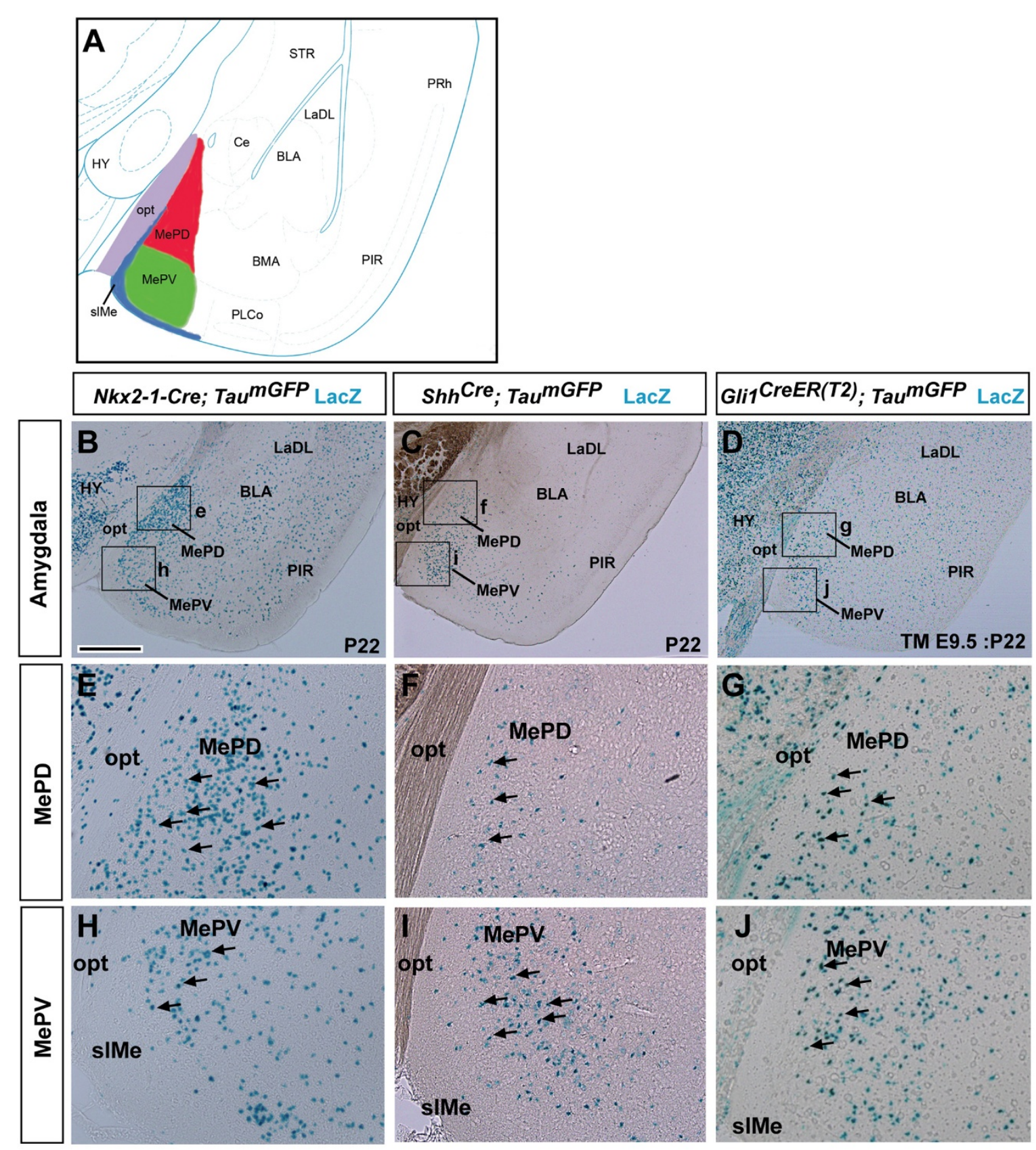

Figure 2 Nkx2-1- and Shh-lineage cells preferentially fate-map to complementary subdivisions of the posterior medial amygdala. (A) Schema of a caudal coronal section of an adult mouse brain showing the nuclei of the amygdala. The medial posterodorsal nucleus (MePD; red) is located lateral to the optic tract (opt; purple), and the medial posteroventral nucleus (MePV; green) is located ventrally and is bordered by the superficial layer of the medial nucleus (sIMe; blue), which is a cell sparse fiber tract. (B,E,H) LacZ staining in postnatal day 22 (P22) Nkx2-1-Cre; TaumGFP brains ( $n=2$ ) revealed that most recombined cells are found in the MePD (E, arrows), with fewer cells in the MePV (H, arrows). (C,F,I) Shh-producing cells revealed the opposite whereby more LacZ+ cells were observed in the MePV (I, arrows) of P22 ShhCre; TaumGFP brains $(n=2)$ than the MePD (F, arrows). (D, G,J) A single dose of tamoxifen administered at E9.5 (TM E9.5: P22; tamoxifen at E9 and survival to P22) resulted in numerous LacZ+ cells in Glif CreER(T2); TaumGFP brains $(n=2)$. In this case, more recombined cells were observed in the MePD than MePV (G,J, arrows) of the posterior MeA. Abbreviations: BLA, basolateral amygdala nucleus; BMA, basomedial amygdala nucleus; Ce, central nucleus; HY, hypothalamus; LaDL, dorsolateral subdivision of the lateral amygdala nucleus; PIR, piriform cortex; PLCo, posterolateral cortical amygdala nucleus; PRh, perirhinal cortex; STR, striatum. Scale bar: $600 \mu \mu m$ (B-D); $200 \mu \mathrm{m}(\mathrm{E}-J)$. 


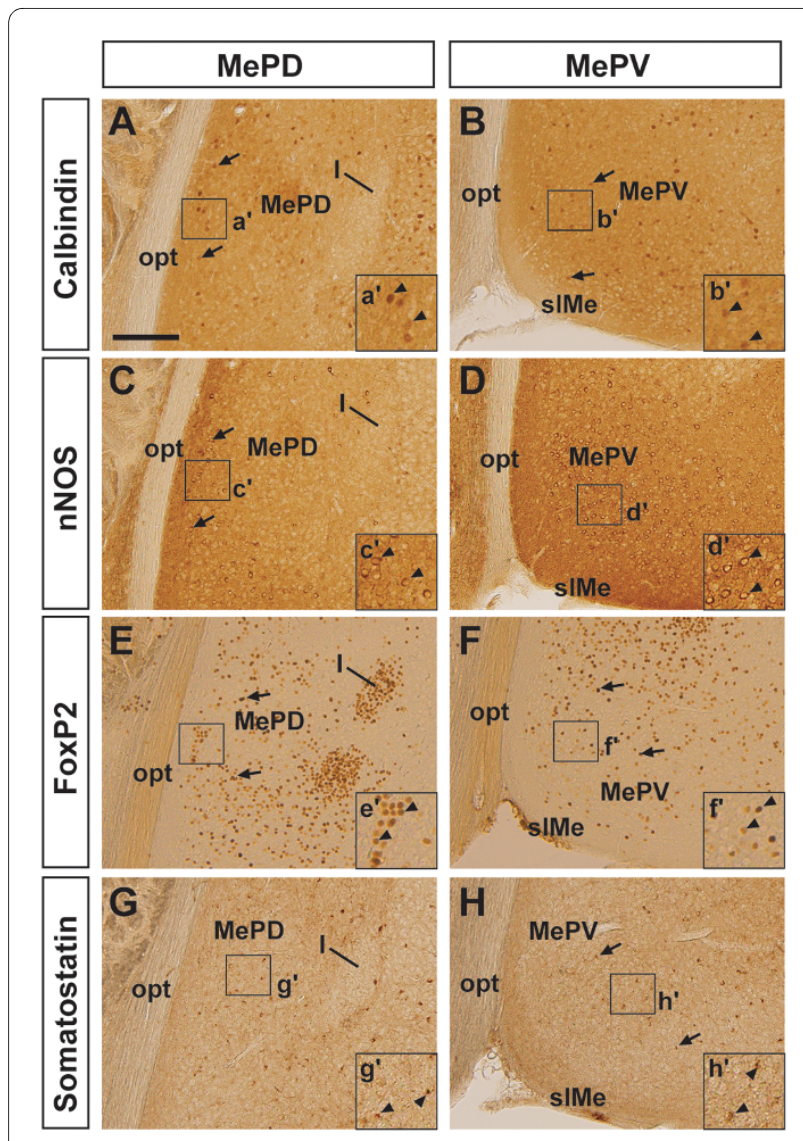

Figure 3 Expression patterns of inhibitory neuronal markers in the MePD and MePV. (A-H) Permanent immunohistochemistry in P22 wild-type brains $(n=3)$ showing the expression of classic inhibitory neuronal markers in the MePD $(A, C, E, G)$ and MePV $(B, D, F, H)$ of the posterior MeA. Calbindin ( $A, B$, arrows), neuronal nitric oxide synthase (nNOS) (C,D, arrows), FoxP2 (E,F, arrows) and Somatostatin $(G, H$, arrows) expression was observed in both nuclear subdivisions of the posterior MeA. (a'-h') High-power views of boxed regions in corresponding panels. Abbreviations: I, intercalated nuclei of the amygdala, opt, optic tract; sIME, superficial layer of the medial nucleus. Scale bar: $200 \mu \mathrm{m}$.

were from the $N k x 2-1-C r e$ lineage as opposed to $31 \%$ (3,733 versus 1,690 out of 5,423 cells, $n=2$ ) from the $S h h^{-}$ Cre lineage, which was highly statistically significant $(P<$ 0.01). The MePV revealed the exact opposite as $69 \%$ of $\beta$ $\mathrm{gal}^{+}$cells were derived from the $S h h^{C r e}$ lineage and the Nkx2-1-Cre lineage contributed only $31 \%$ (3,132 versus 1,384 out of 4,516 cells, $n=2$ ), which was also highly statistically significant $(P<0.01)$. From a single dose of tamoxifen administered at E9.5, in the inducible Gli1 $\operatorname{CreER(T2)}$ line we observed that $61 \%$ of recombined cells $\left(1,976\right.$ out of $3,265 \beta$-gal ${ }^{+}$cells, $\left.n=2\right)$, were located in the MePD. The contribution to the MePV, however, was lower ( $39 \% ; 1,289$ out of $3,265 \beta$-gal ${ }^{+}$cells, $\left.n=2\right)$, and significantly different $(P<0.01)$ from the MePD. Thus, consistent with the qualitative observations shown in Fig- ure 2, these data reveal a significant differential distribution of Nkx2-1- and Shh-lineage cells in the MePD and MePV, respectively, with Gli1-derived cells showing a more significant contribution to the MePD.

Next, we analyzed the percentage co-expression of the markers Calbindin, nNOS, FoxP2 and SST in recombined cells in all three Cre lines. Calbindin was expressed by almost half of the recombined cells in the MePD of $N k \times 2$ 1-Cre (43 $\pm 13 \%, n=740 \beta$-gal $^{+}$cells; Figure 4A, A'), Shh Cre $\left(46 \pm 16 \%, n=350 \beta-\mathrm{gal}^{+}\right.$cells; Figure 4B, B') and Gli1 ${ }^{C r e E R(T 2)}$ brains $\left(39 \pm 4 \%, n=476 \beta\right.$-gal $^{+}$cells; Figure $\left.4 \mathrm{C}, \mathrm{C}^{\prime}\right)$. As mentioned previously, nNOS is expressed in a relatively low number of cells in the MePD compared to the MePV. Interestingly, for the MePD, the contributions of the Nkx2-1 lineage $\left(20 \pm 10 \%, n=1,200 \beta\right.$-gal $^{+}$cells; Figure 4D, D') and the Shh-lineage $(22 \pm 3 \%, n=432 \beta$ $\mathrm{gal}^{+}$cells; Figure $\left.4 \mathrm{E}, \mathrm{E}^{\prime}\right)$ to the nNOS population were remarkably similar. This likely reflects the contribution of the preoptic domains PPOA1 and PPOA2 in which $N k \times 2$ 1 and Shh are co-expressed [19] and is consistent with previous work from our laboratory showing that $D b x 1^{+}$ cells from the POA generate nNOS ${ }^{+}$cells in the MeA [3]. Furthermore, from early-labeled Gli1 $\operatorname{CreER(T2)}$ (TM E9.5) brains we found that MePD nNOS+ cells also derive from this $S h h$-responding population $\left(15 \pm 6 \%, n=621 \beta\right.$-gal ${ }^{+}$ cells; Figure 4F, F'). In addition, FoxP2 ${ }^{+}$cells were derived from both $N k x 2-1$ (37 $\pm 10 \%, n=903 \beta$-gal ${ }^{+}$cells; Figure 4G, G') and Shh $\left(27 \pm 12 \%, n=477 \beta\right.$-gal ${ }^{+}$cells; Figure $4 \mathrm{H}$, $\left.\mathrm{H}^{\prime}\right)$ lineages in the MePD, although this difference was not statistically significant $(P=0.48)$. Gli1-derived cells co-expressing FoxP2 were abundant in the MePD $(23 \pm$ $6 \%, n=450 \beta-$ gal $^{+}$cells; Figure $4 \mathrm{I}, \mathrm{I}$ '), showing that progenitor cells that respond to Shh signaling from an early developmental stage generate this inhibitory cell type in the posterior MeA. Interestingly, in the MePD we found a statistically significant $(P<0.01)$ difference in the generation of SST-positive cells from the Nkx2-1-lineage cells $\left(10 \pm 1 \%, n=1116 \beta\right.$-gal $^{+}$cells; Figure $4 J$ J J') versus the Shh-lineage cells $\left(2 \pm 2 \%, n=431 \beta\right.$-gal $^{+}$cells; Figure $4 \mathrm{~K}$, $\left.\mathrm{K}^{\prime}\right)$. $\mathrm{SST}^{+}$cells were also significantly generated from Gli1-expressing progenitors $\left(20 \pm 10 \%, n=590 \beta\right.$-gal $^{+}$ cells; Figure $4 \mathrm{~L}, \mathrm{~L}$ )', which has also been observed for the cerebral cortex [36].

In the MePV, we also found that recombined cells from all three Cre lines showed high co-expression of Calbindin, indicating an inhibitory neuronal phenotype. As expected, a large number of recombined cells from the Nkx2-1 lineage co-expressed Calbindin $(60 \pm 14 \%, n=$ $282 \beta$-gal ${ }^{+}$cells; Figure $\left.5 \mathrm{~A}, \mathrm{~A}^{\prime}\right)$, although the percentage values determined from $\operatorname{Shh}$ Cre $\left(46 \pm 11 \%, n=761 \beta\right.$-gal ${ }^{+}$ cells; Figure 5B, B') and Gli1 CreER(T2) (TM E9.5) brains (48 $\pm 9 \%, n=300 \beta$-gal $^{+}$cells; Figure $5 \mathrm{C}, \mathrm{C}^{\prime}$ ) were slightly lower, but similar to the MePD values. As shown earlier, 


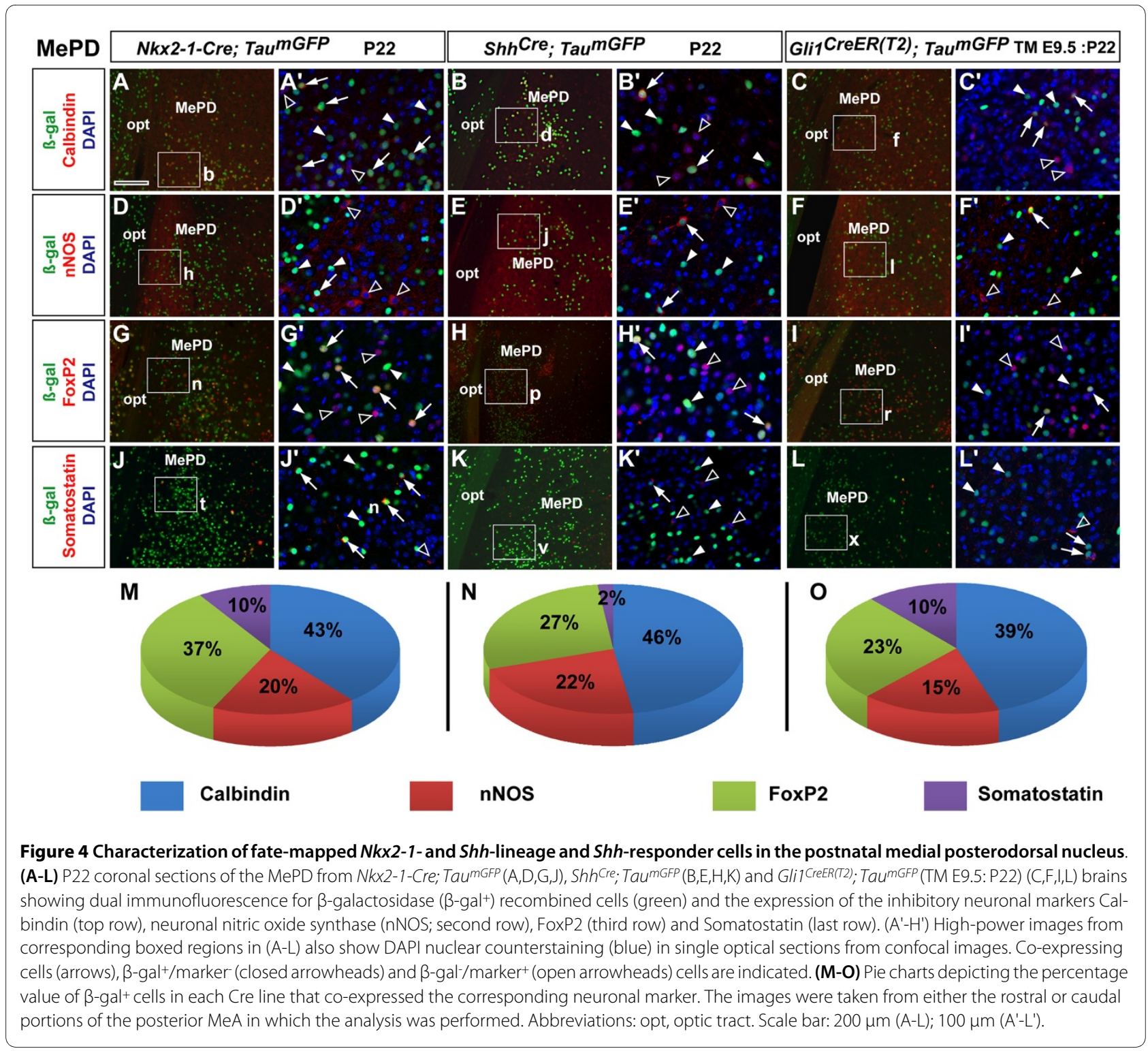

nNOS expression between the two nuclei is disproportionately higher in the MePV (Figure 6), which is preferentially attributed to the Shh-lineage cells. Accordingly, we found that $S h h^{\text {Cre }}$ recombined cells had high coexpression with nNOS (68 $\pm 11 \%, n=884 \beta$-gal ${ }^{+}$cells; Figure $\left.5 \mathrm{E}, \mathrm{E}^{\prime}\right)$, whereas $N k x 2-1$-lineage cells generated a much lower proportion of nNOS ${ }^{+}$cells $(13 \pm 6 \%, n=331$ $\beta$-gal ${ }^{+}$cells; Figure 5D, D'), which was statistically significant $(P<0.05)$ between both groups. The Shh-responding cell population also co-expressed nNOS $(29 \pm 11 \%, n=$ $461 \beta$-gal ${ }^{+}$cells; Figure 5F, F') in the MePV. Similar to the $\mathrm{MePD}$, all recombined cells from both genetic lineages co-expressed FoxP2 in the MePV. Likewise, a higher percentage of co-localization was found in the Nkx2-1-Cre (32 $\pm 10 \%, n=357 \beta$-gal ${ }^{+}$cells; Figure $5 \mathrm{G}, \mathrm{G}$ ) than the ShhCre brains $\left(27 \pm 13 \%, n=940 \beta\right.$-gal ${ }^{+}$cells; Figure $5 \mathrm{H}$,
$\left.\mathrm{H}^{\prime}\right)$, although this did not reach statistical significance. A similar percentage co-expression was observed in the Gli1CreER(T2) (TM E9.5) brains $\left(24 \pm 10 \%, n=310 \beta\right.$-gal ${ }^{+}$ cells; Figure 5I, I'). Finally, we quantified the occurrence of $\beta$-gal/SST double positive cells in the MePV. Interestingly, we also found a preferential bias for the $N k x 2-1$ lineage to generate $\mathrm{SST}^{+}$cells in the MePV $(23 \pm 4 \%, n=414$ $\beta$-gal ${ }^{+}$cells; Figure 5J, J'), as apposed to the ShhCre lineage ( $3 \pm 2 \%, n=547 \beta$-gal ${ }^{+}$cells; Figure $\left.5 \mathrm{~K}, \mathrm{~K}^{\prime}\right)$. Gli1-derived cells also had high co-expression with SST $(24 \pm 10 \%, n=$ $310 \beta$-gal+ cells; Figure 5L, L').

In summary, these data revealed that: Nkx2-1- and Shhlineage cells show a complementary distribution between the dorsal and ventral subdivisions in the adult posterior MeA - in contrast, Gli1-derived neurons contribute more predominantly to the MePD but heavily to both subdivi- 


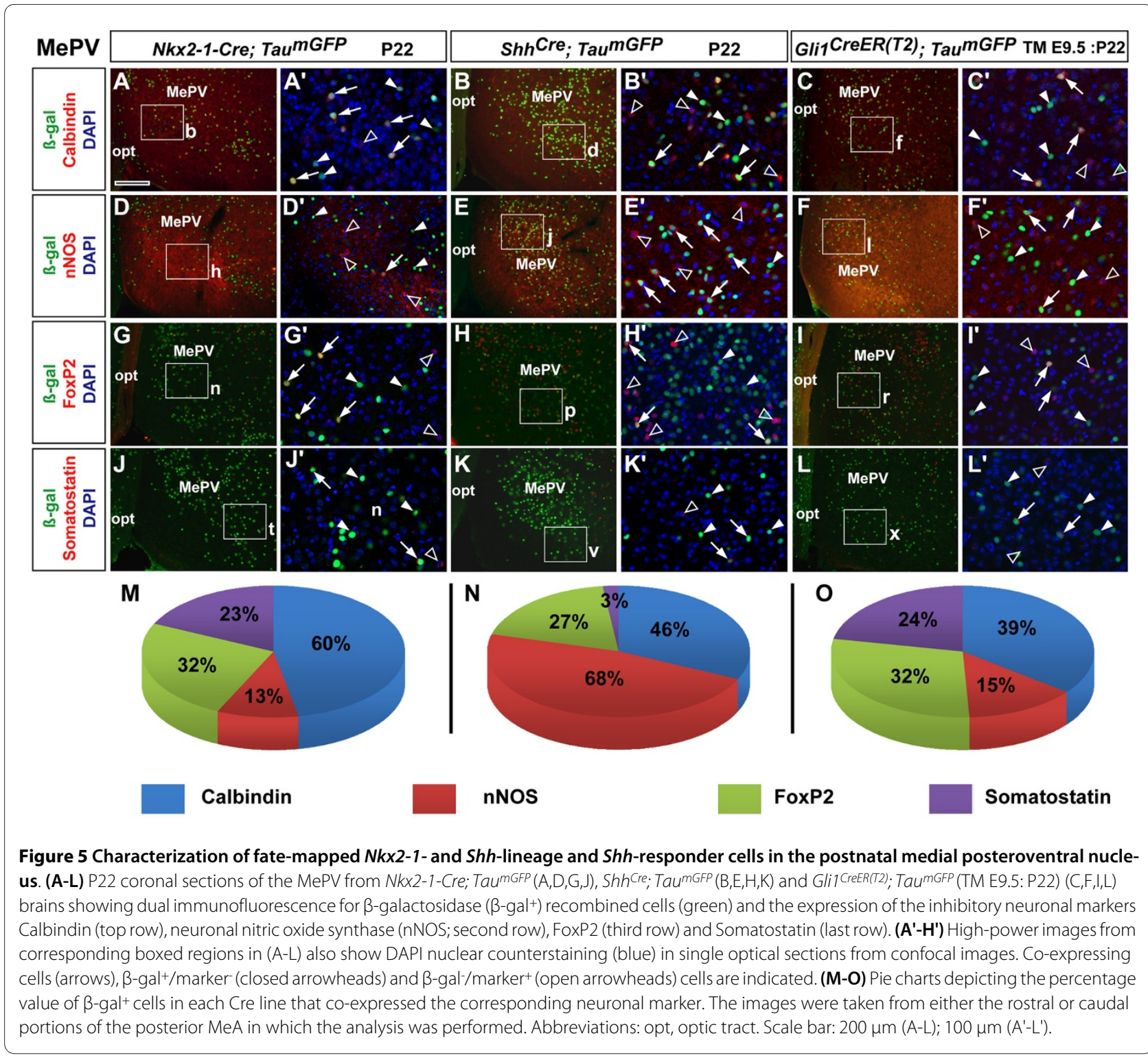

sions; nNOS+ cells, which are preferentially localized in the MePV, are primarily derived from Shh-lineage cells; $N k x 2$-1-lineage cells generated a higher proportion of $\mathrm{SST}^{+}$cells in the MePD and MePV than Shh-lineage cells; Nkx2-1-derived cells showed a higher co-expression with FoxP2 than Shh-lineage cells, although within both lineages there was no discrimination between the MePV and the MePD; and early-generated $\mathrm{Gli1}^{+}$progenitor cells generated inhibitory neuronal cells in proportions similar to those derived from the $N k x 2-1$ lineage.

\section{Nkx2-1 mutant analysis demonstrates a greater functional} role for Nkx2-1 in the MePD compared to the MePV

Having shown that the $N k x 2-1$ lineage contributes to neural diversity in the posterior MeA, we next sought to determine whether there is a functional requirement for
$N k x 2-1$ in the generation of these cell types. To this end, we analyzed the expression of genes that mark the abovedescribed inhibitory neurons in $N k x 2-1$ mutant mice [37]. This analysis was accomplished at E18.5, the latest stage possible due to perinatal lethality. First, we used GAD67 mRNA expression as a pan-inhibitory neuronal marker, which in controls is abundantly expressed throughout the whole telencephalon, including the hippocampus, cortex, striatum and amygdala (Figure 6A). In agreement with prior studies [18,38,39], we observed a major reduction in GAD67 mRNA expression throughout the $N k \times 2-1$ mutant telencephalon, including the posterior MeA (Figure 6B). In particular, the MePD displayed intense GAD67 mRNA expression in the control (Figure $6 \mathrm{~A}$ ), which was reduced in the absence of $N k x 2-1$ (Figure $6 \mathrm{~B})$. The mutant MePV also showed a clear reduction in 


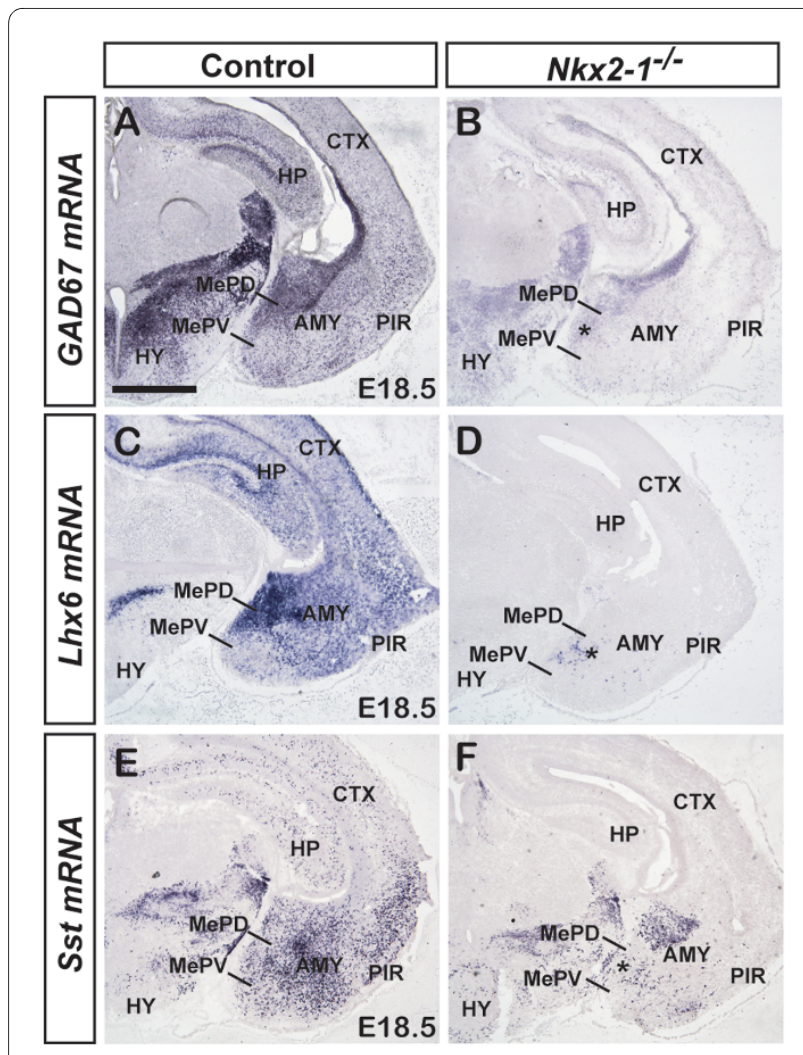

Figure 6 Major defects in mRNA expression of putative inhibitory neuronal subtypes in the MePD of Nkx2-1 mutant mice. (A-F) mRNA expression in E18.5 control (A,C,E) or Nkx2-1 mutant (B,D,F) posterior MeA reveals significant defects in inhibitory neuronal subtypes, particularly in the MePD. (A,B) The mRNA expression of GAD67, a paninhibitory marker, is severely reduced in Nkx2-1 mutant mice (B) compared to controls (A). This is particularly evident in the MePD of the mutant (B, asterisk) as GAD67 mRNA expression appears stronger in the MePD in controls (A). (C,D) The Lhx6 mRNA expression in controls (C) is similar to that observed for GAD67, being notably stronger in the MePD than MePV. Although it is known that Nkx2-1 directly regulates $L h \times 6$ expression, remnant $L h \times 6 \mathrm{mRNA}$ expression was observed in the mutant posterior MeA, particularly around the MePD ( $D$, asterisk). (E,F) The

same was observed for Sst mRNA, whereby the expression in the control MePD (E) was significantly reduced in the mutant $(F)$, although some remnant expression of Sst was observed in the MePD (F, asterisk). $n=4$ for both control and Nkx2-1 mutant for each gene. Abbreviations: AMY, amygdala; CTX, cortex; HP, hippocampus; HY, hypothalamus; PIR, piriform cortex. Scale bar: A-F: $500 \mu \mathrm{m}$.

GAD67 mRNA expression compared to control (Figure 6A, B). Next, we examined the expression of $L h x 6$, which, similar to GAD67, exhibited notably more intense expression in the MePD than the MePV in control brains (Figure $6 \mathrm{C}$ ). Prior studies have described a complete loss of Lhx6 in the Nkx2-1 mutant telencephalon [18,40], which was later explained by the demonstration that $N k \times 2-1$ directly regulates $L h x 6$ transcription [17]. Therefore, we were surprised to find a subset of cells in the posterior MeA that expressed Lhx6 mRNA in the Nkx2-1 mutant (Figure 6D). These 'remnant' Lhx6 mRNA-expressing cells were located in the MePD, whereas the MePV was devoid of Lhx6 expression (Figure 6D). Subsequently, we examined Sst mRNA expression. In control, there were numerous Sst mRNA-expressing cells in the MePD, whereas the MePV contained only a few positive cells (Figure 6E). However, similar to $L h x 6$, we observed a number of remaining Sst mRNA-expressing cells that were primarily observed in the MePD (Figure 6F). This is in interesting contrast to other areas of the telencephalon, such as the cerebral cortex and hippocampus, that display a complete absence of Sst mRNA-expressing cells. A large number of Sst mRNA-expressing cells in the central nucleus was also maintained in the absence of $N k \times 2-1$ (Figure 6F).

This analysis demonstrates that $N k x 2-1$ plays an important role in the specification of inhibitory neuronal subtypes in the posterior MeA. Surprisingly, however, we noticed that a population of cells that expressed $L h x 6$ and Sst mRNA persisted in the MePD in the Nkx2-1 mutant. Therefore, in interesting contrast to the cerebral cortex, a small population of posterior MeA $L h x \sigma^{+}$and $S s t^{+}$cells is not dependent on $N k \times 2-1$ function.

To further explore the potential differential function of $N k x 2-1$ in the MePD and MePV, we examined the expression of genes that specifically mark the MePV, such as Cck, Shh, $L h \times 9$ and nNOS in Nkx2-1 mutants (Figure 7). In the absence of $N k \times 2-1$, there was no noticeable change in Cck mRNA expression in the mutant MePV compared to control (Figure 7A, B). Next, we analyzed $L h x 9$, which is expressed in the embryonic and postnatal MePV $[2,12,41]$. Previous studies have shown that $L h x 9$ mRNA expression is restricted to the superficial layer of the posterior MeA and the MePV [41]. In our hands, a prolonged exposure (up to 48 hours) revealed a signal, albeit weak, in the body of the MePV in both control and mutant brains. When compared to $L h x 9$ mRNA expression in the control MePV (Figure 7C), expression in the mutant was present but appeared weak (Figure 7D), possibly indicating a subtle effect by the absence of $N k \times 2-1$. We next examined the expression of $S h h$, which is expressed in the embryonic MePV [2]. Previously it was shown that at earlier developmental stages in the Nkx2-1 mutant, most telencephalic expression of Shh mRNA is lost, with the exception of a small domain caudally that corresponds to the prospective amygdala [23]. When examined at E18.5, the expression of Shh mRNA that is observed in the control MePV (Figure 7E) is maintained in the mutant MePV (Figure 7F), although the expression domain is significantly smaller. Lastly, we examined the expression of nNOS, where expression is notably higher in the MePV than the MePD [33]. Permanent immunohistochemistry for nNOS showed strong expression in the control MePV (Figure 7G), which, interestingly, does not appear to be significantly altered in the $N k \times 2-1$ mutant (Figure $7 \mathrm{H}$ ). 


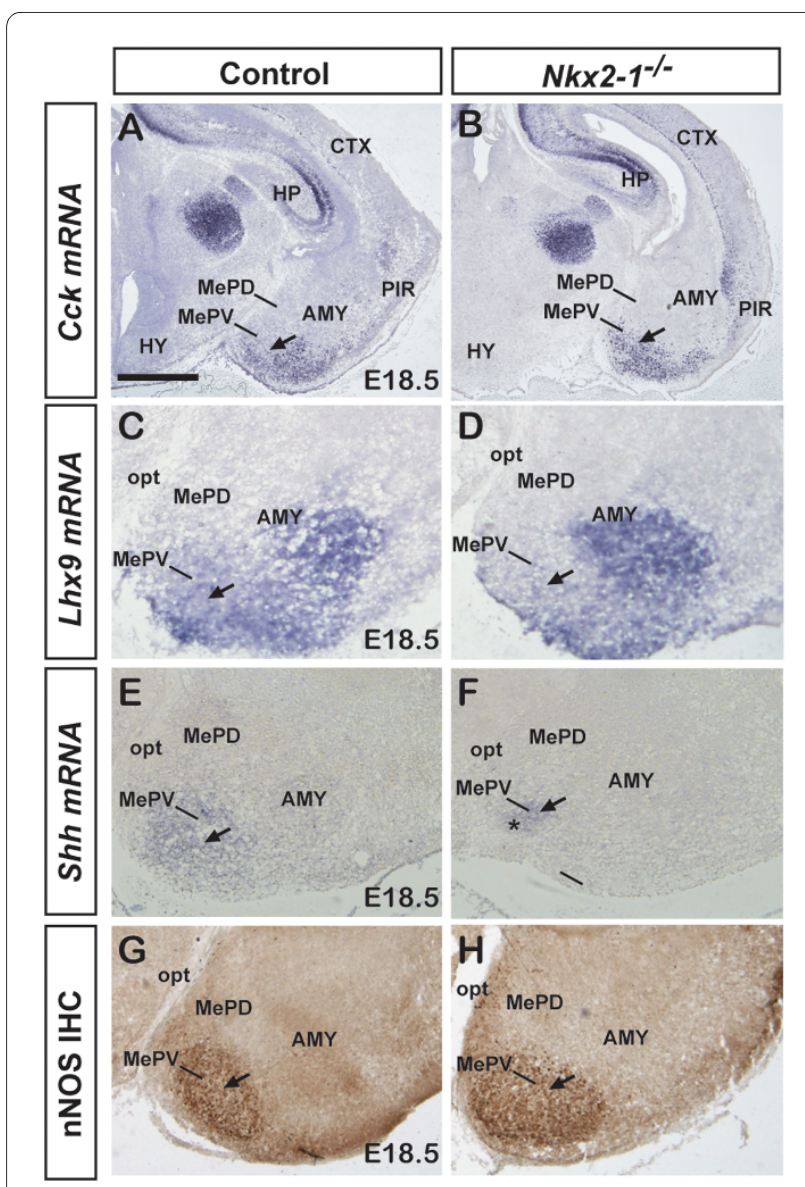

Figure 7 Subtle defects in mRNA and protein expression of putative inhibitory neuronal subtypes in the MePV of Nkx2-1 mutant mice. (A-H) mRNA and protein expression in E18.5 control $(A, C, E, G)$ or Nkx2-1 mutant $(\mathrm{B}, \mathrm{D}, \mathrm{F}, \mathrm{H})$ posterior MeA reveals subtle or no apparent defects in inhibitory neuronal subtypes in the MePV. $(A, B)$ The mRNA expression of $C c k$ does not appear to be altered in Nkx2-1 mutant mice ( $B$, arrow) compared to control (A, arrow). (C,D) Lhx9 mRNA expression, which in controls is found in the MePV (C, arrow) is observed in the mutant MePV ( $D$, arrow), although the expression appears to be weaker. $(E, F)$ Shh mRNA expression, which is found in the control MePV (E, arrow), is maintained in the absence of $N k \times 2-1$, albeit in a reduced expression domain ( $F$, arrow). (G,H) Permanent immunohistochemistry for nNOS shows a large cluster of immunopositive cells in both the control (G, arrow) and mutant MePV (H, arrow), indicating that Nkx2-1 does not play a significant role in specification or maintenance of MePV cell populations. $n=3$ for both control and $N k \times 2-1$ mutant for each gene and for nNOS immunohistochemistry. Abbreviations: AMY, amygdala; CTX, cortex; HP, hippocampus; HY, hypothalamus; opt, optic tract; PIR, piriform cortex. Scale bar: $500 \mu \mathrm{m}(\mathrm{A}, \mathrm{B}) ; 250 \mu \mathrm{m}$ (C-F); $300 \mu \mathrm{m}$ $(\mathrm{G}, \mathrm{H})$.

In summary, the $N k x 2-1$ mutant analysis at E18.5 suggests a functional role for this gene in both the MePD and $\mathrm{MePV}$, with primary effects on the MePD. This is consistent with the fate-mapping analysis (Figure 2) in which $N k \times 2$-1-lineage cells show a major contribution to the MePD.

\section{Electrophysiological characterization reveals three distinct functional classes of Shh-lineage neurons in the posterior MeA}

The overlapping pattern of Shh and $D b x 1$ expression in the embryonic POA [19], and the remarkable similarity in distribution and high percentage of nNOS co-localization between Dbx 1-derived [3] and Shh-derived neurons (Figure 5) raised the question as to whether there were functional differences in these two lineages. To examine this we performed an electrophysiological characterization of Shh-lineage populations in the posterior MeA. In order to visualize the recombined cells, we crossed $S h h^{C r e}$ mice with the RYFP reporter line, which our group has previously found to facilitate electrophysiological analysis $[3,8]$. Importantly, the distribution of recombined $S h h C r e$ cells in the RYFP reporter line was identical to that of the Ta $^{\text {mGFP }}$ reporter line (Additional file 2A, B). We carried out whole-cell patch clamp recordings of recombinant $\mathrm{YFP}^{+}$neurons from $\mathrm{Shh}$ Cre; RYFP mice at P17 to P23. Each recorded neuron was filled with biocytin and slices were subsequently fixed and immunostained for nNOS and FoxP2. From this analysis, we could discriminate three populations of $\mathrm{YFP}^{+}$neurons that exhibited distinct responses to a hyperpolarizing current injection, and also differed in their firing pattern and immunohistochemical profile (Figure 8; Additional file 3).

When hyperpolarized to $-100 \mathrm{mV}$ by injecting a step current (-40 to $120 \mathrm{pA}, 1,000 \mathrm{~ms})$, the first class of YFP ${ }^{+}$ neurons (class I; 9 out of 28 neurons) was characterized by clear depolarizing sag current $(5.5 \pm 2 \mathrm{mV} ; n=9)$, usually resulting in a single rebound spike upon repolarization ( $n=7$ out of 9; Figure 8A). A small depolarizing step current at rheobase value (10 to $40 \mathrm{pA}, 1,000 \mathrm{~ms}$ ) typically induced a series of three to four spikes separated by relatively large and slow rising afterhyperpolarization (amplitude $=-11.2 \pm 2.5 \mathrm{mV}$; decay half-time $=50.7 \pm$ $14.7 \mathrm{~ms}$ ). Larger depolarizing current steps (100 to 200 pA, 1,000 ms) were injected to determine their maximal discharge frequency $(24 \pm 5 \mathrm{~Hz})$ and showed accommodating firing patterns (accommodation ratio $=0.46 \pm$ 0.08). Post hoc immunohistochemical analysis showed that all neurons in this class were $\mathrm{nNOS}^{+} / \mathrm{FoxP}^{-}$(Figure $8 \mathrm{~B})$, with the exception of one cell that was immunonegative for both markers. Interestingly, both the electrophysiological and immunohistochemical profile of this first class of $\mathrm{YFP}^{+}$neurons made them indistinguishable from nNOS ${ }^{+}$MeA neurons generated from the $D b x 1$-derived progenitors previously described by our laboratory [3].

A second class of $\mathrm{YFP}^{+}$neurons (class II; 8 out of 28 neurons) could be distinguished by their inability to repetitively fire even when large depolarizing currents were injected (100 to $300 \mathrm{pA}, 1,000 \mathrm{~ms}$ ) (Figure 8C). These neurons exhibited a single or dual spike discharge 


\section{Shh-Cre; RYFP+ Class I neuron}
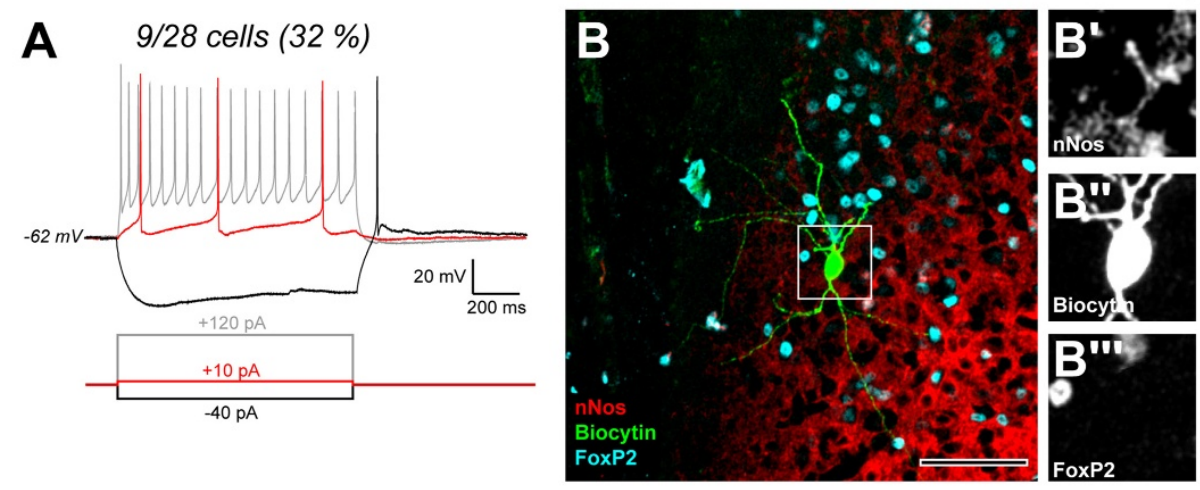

\section{Shh-Cre; RYFP+ Class II neuron}
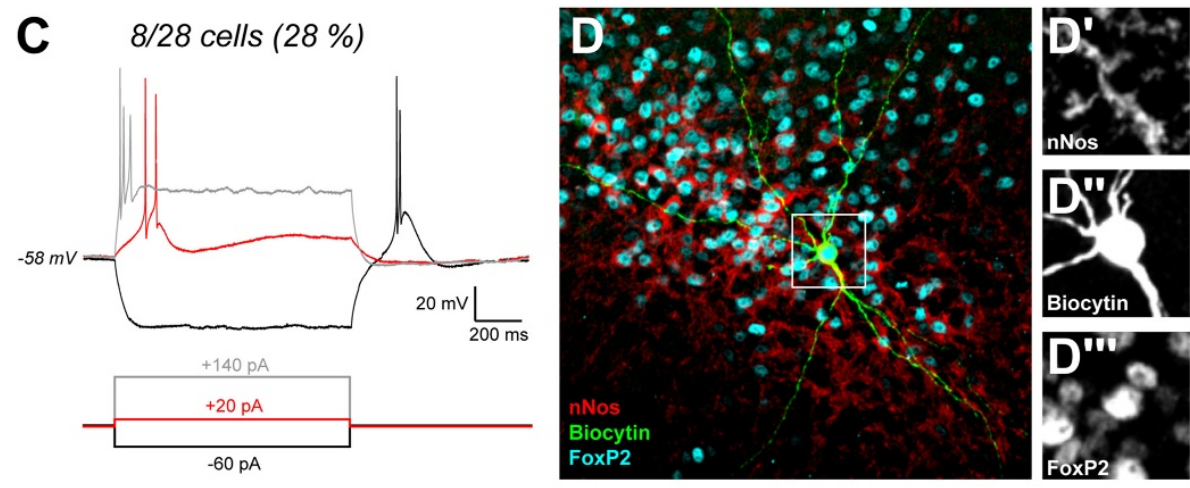

\section{Shh-Cre; RYFP+ Class III neuron}
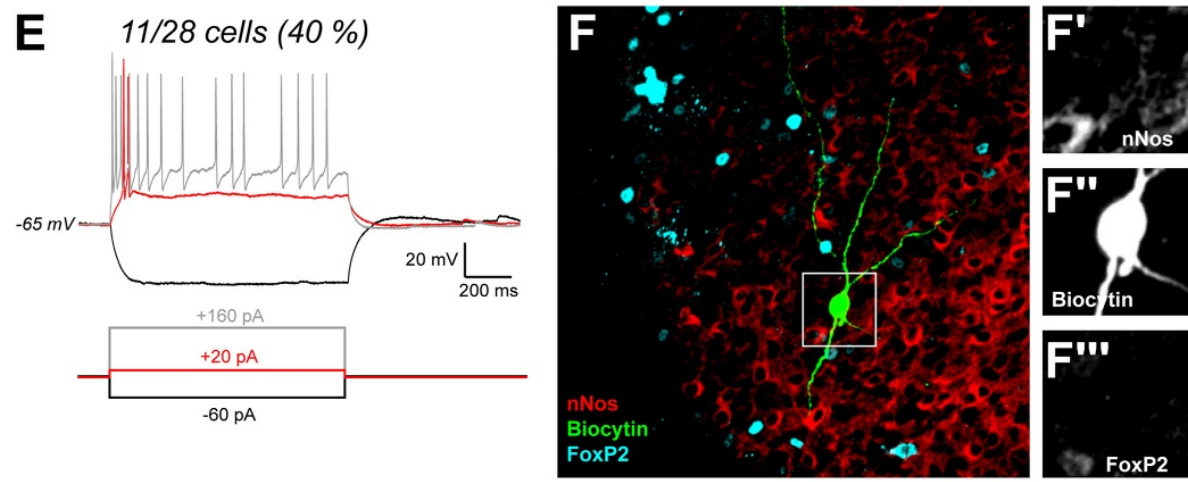

Figure 8 Electrophysiological characterization reveals three functionally distinct classes of Shh-lineage cells in the posterior medial amygdala. (A-F) Representative examples of three classes of $S h h_{C r e}$; RYFP+ neurons recorded by patch-clamp in current-clamp mode (A,C,E), filled with biocytin (B,D,F; green) and immunostained for nNos (B,D,F; red) and FoxP2 (B,D,F; blue). (B'-B'"', D'-D'",F'-F"') Single optical sections from high-power confocal imaging of biocytin, nNOS or FoxP2 immunohistochemistry. Each neuron was recorded at its resting membrane potential, as given at the left of each group of traces. Neurons were subjected to a hyperpolarizing step (A,C,E; black) to test for the presence of sag current and rebound firing, a small depolarizing step corresponding to the rheobase of the neuron $(A, C, E ;$ red) and the minimal depolarizing step able to induce firing at a maximum frequency ( $A, C, E ;$ grey). Current injection step values are indicated in the bottom of each recording and accordingly colored. The fraction and percentage of ShhCre; RYFP+ neurons corresponding to each class are indicated on the top of each group of traces. Scale bar: $80 \mu \mathrm{m}(\mathrm{A}-\mathrm{H}) ; 40 \mu \mathrm{m}$ (B'-E'"). 
upon depolarization. At rheobase value (20 to $80 \mathrm{pA})$, the discharge systematically rode on a slow-depolarizing envelope (amplitude $=18 \pm 8 \mathrm{mV}$ ), suggesting the presence of a low-threshold $\mathrm{Ca}^{++}$current $\left(\mathrm{I}_{\mathrm{T}}\right)$. These neurons were exempt of sag currents when hyperpolarized to -100 $\mathrm{mV}$ but would exhibit a slow-depolarizing envelope upon repolarization, confirming the likely presence of large $\mathrm{I}_{\mathrm{T}}$ currents in these cells. Interestingly, all of these neurons were FoxP2 ${ }^{+}$and most were also nNOS ${ }^{+}(6$ out of 8 cells; Figure 8D).

The third class of YFP+ neurons (class III; 11 out of 28 neurons) was characterized by an irregular firing (frequency 5 to $20 \mathrm{~Hz}$ ) in response to a large depolarization (Figure $8 \mathrm{E}$ ). At rheobase value (20 to $80 \mathrm{pA}$ ), these neurons displayed a single early discharge of one to three spikes riding a small depolarizing envelope $(10 \pm 5 \mathrm{mV})$ and exhibited sharp fast-rising afterhyperpolarization (amplitude $=-13.2 \pm 1.5 \mathrm{mV}$; decay half-time $=15.4 \pm 4.2$ $\mathrm{ms})$. In response to larger depolarizing current steps (100 to $200 \mathrm{pA}, 1,000 \mathrm{~ms}$ ), these cells exhibited a very variable maximal discharge frequency $(11 \pm 5 \mathrm{~Hz})$ ranging from a single initial burst of three to five spikes to a series of two or three bursts of three to five spikes each. When hyperpolarized to $-100 \mathrm{mV}$, these cells exhibited no or a minimal sag current $(1.5 \pm 0.8 \mathrm{mV})$ and small rebound $\mathrm{I}_{\mathrm{T}}$-like currents were observed $(10 \pm 5 \mathrm{mV}$ ). In most cells (9 out of 11 cells) these currents were not large enough to induce a rebound spike. All cells in this third class of cells were immunonegative for both nNOS and FoxP2 (Figure $8 \mathrm{~F})$.

Taken together, the results from the electrophysiological and post hoc immunohistochemical analyses revealed that Shh-lineage neurons generate functionally distinct inhibitory neuronal classes in the posterior MeA. We find that in addition to the class I neurons that are similar to neurons derived from the $D b x 1^{+}$lineage [3], at least two other classes of neurons have distinct electrophysiological and molecular profiles. Based on their expression of nNOS, a marker of MeA inhibitory projection neurons, as well as their morphology, we speculate that the classes I and II are inhibitory projection neurons. Our electrophysiological analysis shows that our Shh-lineage class III neurons that lack expression of both nNOS and FoxP2 exhibit electrophysiological characteristics that partially reflect a glutamatergic phenotype in the posterior MeA, which has been suggested by a prior study [42]. However, the restriction of these neurons to a Tbr1-negative region indicates that they may possess inhibitory character. Interestingly, we found that $S h h$-lineage cells gave rise to a subset of deep layer neurons in the cerebral cortex with a pyramidal morphology (data not shown), indicating that these progenitors can give rise to a subset of glutamatergic neurons. However, the vast majority of Shh-lin- eage cells in the amygdala are likely to be inhibitory because the MeA is primarily GABAergic in neuronal output, as shown by intense expression of GAD65 and GAD67 ([1] and this study) and because nNOS [43] and Calbindin, which are expressed in most Shh-lineage neurons, are markers of inhibitory neurons.

\section{Discussion}

Genetic fate-mapping is a powerful tool to elucidate the contribution of progenitor populations marked by individual genes to the cellular diversity found within the adult mammalian forebrain. Using this approach, we correlated the neurochemical phenotypes in the postnatal amygdala with defined domains of gene expression in the embryonic forebrain. With regard to the amygdala, genetic fate-mapping thus far has shown that excitatory neurons in the basolateral complex are derived from the pallial $E m \times 1$ lineage and the ventral pallial $D b x 1$ lineage $[3,8,44]$. In addition, pan-subpallial fate-mapping using the $D l \times 5 / 6$ enhancer shows substantial recombination in the medial and central nuclei as well as the basolateral complex [45], consistent with subpallial sources of amygdala local interneurons and inhibitory projection neurons. Genes with more restricted expression patterns have shown that the subpallial embryonic POA, which expresses $D b x 1$ and $N k x 5-1$, contributes to neural diversity in the MeA $[3,46]$. Here, in agreement with a prior study [5], we show that cells expressing the transcription factor Nkx2-1, which is expressed in the embryonic MGE and POA $[18,19]$, also contributes to inhibitory neuronal diversity in the MeA. Importantly, we significantly extend this knowledge by showing: 1 , that $N k \times 2-1$-lineage cells have a biased contribution to the dorsal subdivision of the posterior MeA (MePD); 2, consistent with this, $N k \times 2-1$ functions to a greater degree in the development of the MePD as opposed to the MePV; 3, Shh-lineage cells generate complementary patterns of cellular diversity in the ventral subdivision of the posterior MeA, with a greater bias toward generation of MePV neurons; 4, Shhresponding (Gli1 $\left.{ }^{\mathrm{CreER}(T 2)+}\right)$ progenitor cells contribute to posterior MeA neural diversity from approximately E10.5 (Figure 9); and 5, neurons derived from the Shh-lineage are a functionally diverse group consisting of at least three classes of neurons as defined from unique combinations of electrophysiological and neurochemical profiles.

\section{Shh- and Nkx2-1-lineage cells generate distinct classes of inhibitory neurons in the posterior MeA}

Shh is the most studied of the Hedgehog family of secreted glycoproteins and is a potent morphogen that plays a crucial role in ventral patterning of many tissues, including the forebrain, midbrain, cerebellum, spinal cord and the limb (reviewed by [47-52]). Here, we used a Cre line under the transcriptional regulation of $\operatorname{Sh}$ [22] to indeli- 


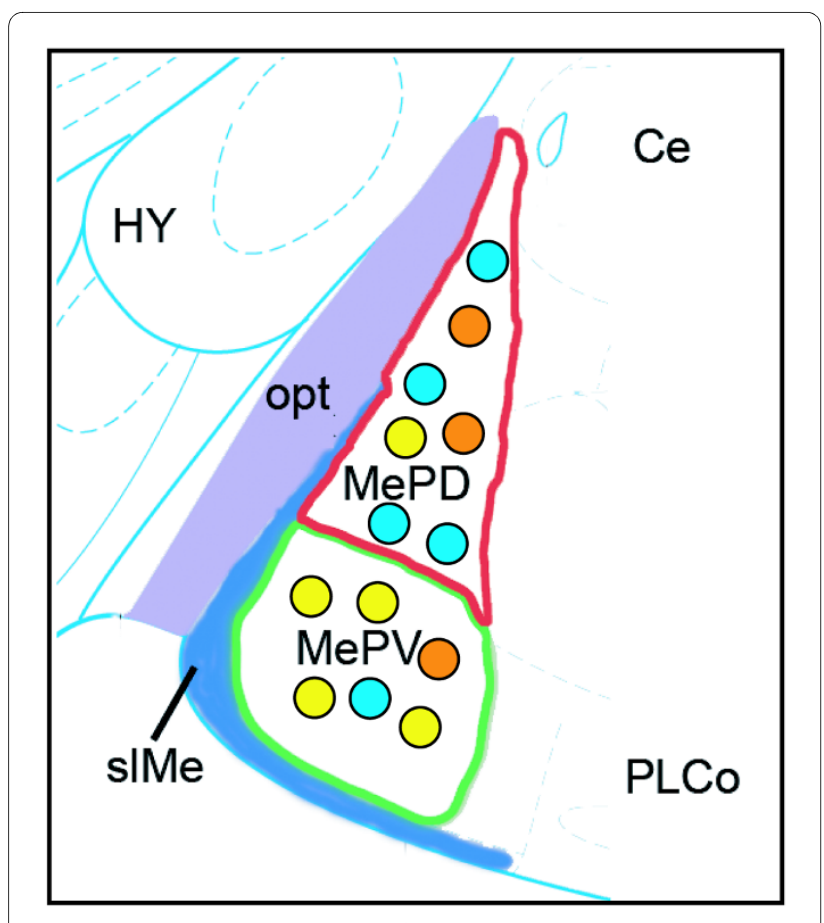

\section{Nkx2-1-derived neurons}

\section{Shh-derived neurons}

\section{Gli1-derived neurons}

Figure 9 Schema of Nkx2-1-, Shh- and Gli1-derived neurons in the dorsal and ventral subdivisions of the posterior medial amygdala. Schema summarizes the fate-mapping data. Nkx2-1-derived neurons (blue colored circles) preferentially fate-mapped to the MePD (MePD, 69\%; MePV, 31\%). Shh-derived neurons (yellow colored circles) were distributed in an exact mirror-image pattern (MePD, 31\%; MePV, 69\%). Similar to Nkx2-1-derived neurons, Gli1-derived neurons (orange colored circles) were found predominantly in the MePD (61\%) compared to the MePV (39\%). The differential inhibitory neuronal subtype fates are summarized in the pie charts in Figures $4 \mathrm{M}, \mathrm{N}, \mathrm{O}$ and $5 \mathrm{M}, \mathrm{N}, \mathrm{O}$. Abbreviations: $\mathrm{Ce}$, central nucleus; $\mathrm{HY}$, hypothalamus; opt, optic tract; PLCo, posterolateral cortical amygdala nucleus; PRh, perirhinal cortex; sIMe, superficial layer of the medial nucleus.

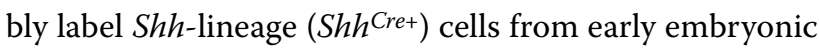
development through to adulthood. Using this genetic fate-mapping tool we were able to identify a predominant contribution of Shh-expressing cells in the generation of inhibitory neural diversity in the MeA. Specifically, we show that $S h$-lineage cells preferentially generate the cells in the MePV, which express nNOS $(68 \%$ of recombined cells), a marker of hypothalamic projecting inhibitory output neurons [43]. Interestingly, a subset of these Shh-lineage, $\mathrm{nNOS}^{+}$cells (the class I type) display electrophysiological and molecular signatures reminiscent of our previously identified Dbx1-derived MeA neurons [3].
Therefore, this subpopulation likely derives from the ventral subdivision of the POA (pPOA2), which expresses $D b x 1$ [3]. Thus, similar to the generation of midbrain dopaminergic neurons [53], Shh-lineage cells appear to give rise to diverse neural subtypes in the telencephalon.

The co-expression of FoxP2 with nNOS in the class II Shh-derived neurons is also quite intriguing. FoxP2 has been identified as essential for development of brain circuitry involved in speech in humans and vocalization in other vertebrates. Mutations in FoxP2 have also been implicated in both language disorders and autism, the latter of which is characterized by both language and amygdala-based impairments (reviewed in $[54,55]$ ). Therefore, it is possible that the electrophysiological and marker diversity of $S h h$-lineage neurons underlies important differences in both pathways of connectivity and function of MeA output neurons. For example, as the $\mathrm{MeA}$ is a central component of circuitry that regulates innate behaviors such as feeding, reproduction, aggression and maternal bonding, perhaps these different Shhlineage populations differentially modulate these behaviors. Developmentally, it is also possible that transcription factor genes that show discrete and overlapping expression domains within the POA, such Dlx1, Nkx6-2, $N k x 5-1$ or $L h x 2[19,46]$, may selectively or combinatorally generate the class I to III electrophysiological subtypes that we describe here. In addition, as Shh and $D b x 1$ are expressed in the embryonic hypothalamus [23,56,57], which itself has been speculated to generate cells destined for the amygdala $[4,6]$, ], further complexity or refinement of neural populations may be related to more precise origins within the developing forebrain.

We also find that, in contrast to Shh-lineage neurons, Nkx2-1-derived cells preferentially fate-map to the $\mathrm{MePD}$, a nucleus that regulates reproductive behaviors. A previous study showed that $N k \times 2-1$-lineage cells generate inhibitory cells in the MeA [5], in addition to the known and recently identified roles for $N k \times 2-1$ in generating inhibitory cells for the cerebral cortex $[5,18,58]$ and globus pallidus $[29,59]$, respectively. We find that analogous to the cerebral cortex, a number of SST ${ }^{+}$cells are $N k \times 2-1$ derived, although another subset are derived from Shhlineage progenitor cells. $N k \times 2-1$-lineage cells show high co-expression with Calbindin and FoxP2 in both the MePD and MePV. Whereas Shh-lineage cells generate the vast majority of nNOS ${ }^{+}$cells in the MePV, Nkx2-1-lineage cells generate an equivalent portion of $\mathrm{nNOS}^{+}$cells within both nuclei. Therefore, this study reveals that inhibitory neural diversity in the posterior MeA is generated from

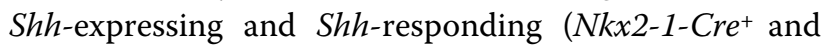
Gli1 $\operatorname{CreER}(T 2)+)$ components of the Shh signaling pathway (see Figure 9 for schematic). 


\section{Function of Nkx2-1 in medial amygdala patterning}

The transcription factor $N k \times 2-1$ plays a major role in the generation of inhibitory neurons in the forebrain $[5,18,60]$ and the expression of Nkx2-1 is largely dependent on Shh [61]. The notable exception to this is at the level of the prospective amygdala, where a small focal expression domain of Shh remains in Nkx2-1 mutants [23]. Interestingly, as previously shown, this remnant expression is coincident with the persistence of markers of the oligodendrocyte lineage [23]. Here, we show that Shh-lineage cells generate inhibitory neurons as shown by the differential expression of Calbindin, nNOS, FoxP2 and SST. Our gene expression analysis in Nkx2-1 mutant embryos revealed that $N k x 2-1$ has a significant functional role in the development of the MePD, where we observed major decreases in GAD67, Lhx6 and Sst mRNA gene expression. This finding is consistent with previous studies that have described a complete loss of Lhx6 mRNA expression in the Nkx2-1 mutant telencephalon [18,40]. Surprisingly, we observed a sparing of a subset of these GAD $67^{+}, L h \times 6^{+}$and $S s t^{+}$neurons in the MeA. As $N k x 2-1$ has more recently been shown to directly regulate $L h x 6$ transcription [17], our results suggest that in at least a subpopulation of amygdala neurons, this might not be the case. Indeed, it is likely that in this spared population, the remnant $S h$ expression domain in the embryonic caudal telencephalon in Nkx2-1-mutant mice is sufficient to directly specify these inhibitory neurons directly.

\section{Fate-mapping of embryonic Gli1 + cells reveal the precocious generation of inhibitory neural diversity in both subdivisions of the posterior MeA compared to other forebrain structures}

Shh signaling is mediated through the Gli family of transcription factors, which are homologous to the Drosophila zinc finger transcription factor cubitus interruptus, which mediates all Hedgehog signaling in the fly [62]. Of the three mammalian Gli family members, Gli1 and Gli2 primarily act as activators whereas Gli3 functions as a repressor [63-65]. Analysis of loss of function mutant mice has shown that Shh signaling is required for the initial transcriptional activation of endogenous Gli1, but not Gli2, in the forebrain [24]. Here, by administering a single tamoxifen dose at E9.5, we were able to label $\mathrm{Gli1}^{+}$Shhresponder cells born from approximately E10.5 in the Gli1 CreER(T2) line, a readout of Shh activity [21]. From this analysis, we show that cells that respond to Shh signaling also contribute to inhibitory neural diversity in the posterior MeA. Co-expression was observed with all inhibitory markers used in this study: Calbindin, nNOS, FoxP2 and SST. Furthermore, numerous $\mathrm{LacZ}^{+}$recombined cells in the MePD and MePV in Gli1 CreER(T2); Tau ${ }^{m G F P}$ (TM E9.5) brains lend credence to prior observations that indicate that neurons of the MeA are born earlier in development than those destined for other amygdala nuclei, such as those of the basolateral complex $[3,4,7,8]$.

\section{Conclusions}

In this study, we have shown that Nkx2-1- and Shh-lineage cells preferentially fate-map to the dorsal and ventral subdivisions of the posterior MeA, with differential contributions to both local and projection inhibitory neurons. Previous tracing studies have identified that MePD efferent neurons project to three interconnected nuclei that are involved in reproductive behaviors: the medial preoptic nucleus, the ventrolateral part of the ventromedial hypothalamic nucleus and the ventral premamillary nucleus. In contrast, projections from the MePV involved in defensive behaviors terminate in the anterior hypothalamic nucleus and the dorsomedial portion of the ventromedial hypothalamic nucleus $[12,66]$. In a behavioral context, the reproductive and defensive actions are closely interrelated, and upon the appearance of threatening behaviors, a 'gate-control' mechanism ensures the rapid shut-down of reproductive behaviors to aid survival. The use of different $L h x$ transcription factors that delineate these projections to their hypothalamic targets may potentially serve as a neural substrate to integrate conflicting reproductive and defensive behavioral cues [12]. Here, we show the inhibitory neural diversity of these nuclei is generated from Shh-expressing and Shhresponsive cells, implicating the $S h h$-pathway component of MeA development. Therefore, the data from the current study provide novel insights into the gene network complexity and genetic mechanisms involved in the development of the MeA.

\section{Materials and methods Animal use}

Mouse lines used in this study were: Swiss-Webster (SW; Taconic Farms, Albany, NY, USA), Nkx2-1 mutant [18], Shh Cre [22], ROSA-YFP [67], Tau ${ }^{m G F P ~[28], ~ G l i 1 ~} \operatorname{CreER(T2)}$ [21] and Nkx2-1-Cre [5]. Mice were maintained according to protocols approved by the Animal Welfare and use committee at Children's National Medical Center, Washington DC, National Institutes of Health, Bethesda, MD, and NYU School of Medicine, NY. Nkx2-1 mutant mice were maintained on a SW background. The Nkx2-1-Cre and $S h h^{C r e}$ lines were maintained on a $\mathrm{C} 57 \mathrm{Bl} / 6$ background, the Gli1 ${ }^{C r e E R(T 2)}$ mice were kept on a SW background and the reporter mice on $\mathrm{C} 57 \mathrm{Bl} / 6 \times \mathrm{SW}$ mixed backgrounds.

\section{Animal crosses and genotyping}

For staging of the embryos, midday of the day of vaginal plug detection was considered as E0.5. The day of birth was considered P0. To avoid potential sexual dimorphic differences in the MeA, only males were used for postna- 
tal analyses. Mice were transcardially perfused with $4 \%$ paraformaldehyde (PFA) and brains were post-fixed in $4 \%$ PFA for at least 6 hours to overnight. Pregnant females from Gli1CreERT2; Ta ${ }^{m G F P}$ crosses were administered a single dose $(100 \mathrm{mg} / \mathrm{kg}$ in corn oil) of tamoxifen (Sigma, St Louis, MO, USA) by oral gavage at E9.5, and embryos collected at E12.5 or pups were perfused at P22. For early embryonic analysis (E10.5 to E13.5) pregnant dams were euthanized by $\mathrm{CO}_{2}$ inhalation and the embryos were harvested by Caesarian section and whole heads were fixed for 2 hours (for X-gal staining) or overnight in 4\% PFA at $4^{\circ} \mathrm{C}$. Pregnant dams of E18.5 litters were anaesthetized with Nembutal and the embryos were transcardially perfused. The isolated brains were post-fixed overnight at $4^{\circ} \mathrm{C}$. Genomic DNA for genotyping was isolated by phenol:chloroform extraction. Mice for fate-mapping and electrophysiological analyses were identified by PCR for Cre [68] and yellow fluorescent protein (YFP) [69] for transgenic and reporter lines, respectively. $N k \times 2-1$ mutant embryos were identified by PCR using a GC rich kit (Roche, Indianapolis, IN, USA) and previously described primers $[18,23]$, and morphologically by the absence of lungs [37].

\section{Tissue preparation and histology}

After rinsing in PBS, postnatal brains were embedded in $4 \%$ agarose and sectioned coronally at a thickness of 50 $\mu \mathrm{m}$ using a Vibroslicer (Leica VT1000S, Leica, Nussloch, Germany). Embryonic brains were cryoprotected by graded sucrose immersion $(10 \%, 20 \%$ then $30 \%$ overnight) and embedded in Tissue-Tek OCT Compound (Sakura Finetek USA Inc., Torrance, CA, USA). Coronal sections at a thickness of 20 (E10.5 to E13.5) or $30 \mu \mathrm{m}$ (E18.5) were collected on glass slides, air-dried and stored at $-20^{\circ} \mathrm{C}$.

\section{Non-radioactive dioxygenin-labeled RNA in situ hybridization}

mRNA in situ hybridization was carried out as described previously [68] with the exception that the reaction product was visualized by NBT/BCIP (Roche) diluted in AP buffer $(10 \mu \mathrm{l} / 100 \mathrm{mM} \mathrm{NaCl}, 100 \mathrm{mM}$ Tris $\mathrm{pH}$ 9.5, $50 \mathrm{mM}$ $\mathrm{MgCl}_{2}$ ). The following cDNA probes were used in this study: Cck, Foxg1, GAD67, Gli1, Lhx6, Lhx9, Nkx2-1, Shh and Sst.

\section{Immunofluorescence}

Free-floating adult vibratome sections were rinsed in PBS prior to blocking in 10\% normal serum (NS) in PBS with Triton 0.03\% (PBST; Sigma) for 1 hour at room temperature (RT), then overnight incubation in the primary antibodies diluted in PBST with 1\% NS at RT for free-floating or $4^{\circ} \mathrm{C}$ for mounted tissue. The sections underwent three 10-minute rinses in PBS and were incubated in the appro- priate donkey anti-Cy3, Cy5 (1:200; Jackson Immunoresearch, West Grove, PA, USA) or donkey anti-Alexa 488 (Invitrogen, Carlsbad, CA, USA) secondary antibodies, diluted in PBST with 1\% normal donkey serum (NDS) for 2 hours at RT. The sections were rinsed twice then incubated in DAPI (1:1,000 in PBS; Sigma) for 10 minutes. The sections were mounted on Superfrost slides and coverslipped using Gel Mount aqueous mounting media (Sigma). The primary antibodies used in distinct combinations were: goat anti- $\beta$-gal (1:500; Biogen, Cambridge, MA, USA), goat anti-FoxP2 (1:500; Santa Cruz Biotechnology Inc., Santa Cruz, CA, USA), goat anti-GFP (1:1,000; Novus Biologicals, Littleton, CO, USA), rabbit anti- $\beta$-gal (1:1,000; ICN Pharmaceuticals Inc, Costa Mesa, CA, USA), rabbit anti-Calbindin (1:1,000; Calbiochem, La Jolla, CA, USA), rabbit anti-nNOS (1:1,000; Sigma), rat anti-GFP (1:1,000; Nacalai USA, San Diego, CA, USA) and rat anti-SST (1:250; Millipore, Billerica, MA, USA).

\section{Permanent immunohistochemistry}

Free-floating adult vibratome sections and E18.5 cryostat sections were rinsed in PBS and incubated in PBS:methanol:30\% $\mathrm{H}_{2} \mathrm{O}_{2}$ (Sigma) in an 8:1:1 ratio for 20 minutes at RT to quench endogenous peroxidases. The sections underwent further rinses in PBS prior to blocking of nonspecific binding sites using 10\% NS in PBST. The primary antibodies were incubated overnight at RT. Further rinses in PBS preceded and followed incubations for 1 hour at RT in biotinylated antibodies (1:500; Vector Labs, Burlingame, CA, USA) then extravidin-peroxidase $(1: 2,000$; Sigma), all diluted in $1 \%$ NS in PBST. The reaction product was visualized using a DAB kit (Vector Labs) according to the manufacturers' instructions. The reaction was stopped in Tris-buffered saline pH7.5 and the sections were mounted and/or coverslipped using permanent mounting media (Sigma). The primary antibodies used were as follows: goat anti-FoxP2 (1:1,000), goat anti-GFP $(1: 1,000)$, mouse anti-Parvalbumin (1:1,000; Sigma), rabbit anti-Calbindin $(1: 2,000)$, rabbit anti-nNOS $(1: 3,000)$, rabbit anti-Tbr1 (1:1,000; kind gift of R Hevner), rabbit anti-Neuropeptide Y (1:1,000; Immunostar, Hudson, WI, USA), rabbit anti-GAD65/67 (1:1,000; Millipore), and rat anti-SST (1:250).

\section{Electrophysiology}

Electrophysiological analysis of Shh-lineage cells in the posterior MeA was performed on male mice at P17 to P21 from Shh ${ }^{C r e}$; ROSA26-YFP crosses. Mice were anesthetized with isoflurane, decapitated, and their brains were removed. Brain hemispheres were rapidly dissected on ice and cut into 300- $\mu \mathrm{m}$ thick coronal sections on a Leica VT100S vibratome in an ice-cold oxygenated solution consisting of (in $\mathrm{mM}$ ) $87 \mathrm{NaCl}, 2.5 \mathrm{KCl}, 1.25$ 
$\mathrm{NaH}_{2} \mathrm{PO}_{4}, 7 \mathrm{MgCl}_{2}, 0.5 \mathrm{CaCl}_{2}, 25 \mathrm{NaHCO}_{3}, 25$ glucose, 75 sucrose $(347 \mathrm{mOsmol})$ at $\mathrm{pH}$ 7.4. Slices were stored in the same solution at $35^{\circ} \mathrm{C}$ for 30 minutes, then transferred into artificial cerebrospinal fluid of the following composition (in mM): $124 \mathrm{NaCl}, 3 \mathrm{KCl}, 2.5 \mathrm{CaCl}_{2}, 1.3$ $\mathrm{MgSO}_{4}, 26 \mathrm{NaHCO}_{3}, 1.25 \mathrm{NaHPO}_{4}, 15$ glucose; saturated with $95 \% \mathrm{O}_{2} / 5 \% \mathrm{CO}_{2}$ at room temperature $\left(20\right.$ to $\left.25^{\circ} \mathrm{C}\right)$.

Slices were transferred to the recording chamber and perfused with artificial cerebrospinal fluid at a rate of 1 to $2 \mathrm{ml} / \mathrm{s}$. Cells were visualized using an upright Olympus BX51W microscope equipped with infrared and fluorescent illumination, Normasky optics, and infrared camera (all from Olympus). Cells were only chosen based on their YFP fluorescence and apparent viability (clear membrane, nucleus not visible) without bias in terms of location within the MePD or MePV, cell size or morphology. Patch electrodes had resistances between 3 and $6 \mathrm{M} \Omega$ when filled with the intracellular solution of the following composition (in $\mathrm{mM}$ ): $130 \mathrm{~K}$-gluconate, $10 \mathrm{NaCl}, 2 \mathrm{Mg}$-ATP, $0.3 \mathrm{Na}$-GTP, 10 HEPES, 0.6 EGTA, biocytin $5 \mathrm{mg} / \mathrm{ml}$, solution adjusted to $\mathrm{pH} 7.2,275$ mOsm (junction potential $=13 \mathrm{mV}$ ). Whole-cell recordings were obtained using a Multiclamp 700B (Molecular Devices, Sunnyvale, CA, USA) and recordings were monitored via a PC running pClamp 9.2 (Molecular Devices). After recording membrane potential, capacitance and resistance values, cells were categorized on the basis of their response to depolarizing and hyperpolarizing current pulses. Off-line analysis was performed using Clampfit 9.2 (Molecular Devices) and Mini Analysis (Synaptosoft Inc., Fort Lee, NJ, USA). In all experiments, data were filtered at $10 \mathrm{kHz}$ during capacitance compensation and $5 \mathrm{kHz}$ during subsequent data recording. The traces were digitized at 10 $\mathrm{kHz}$. All voltage measurements and steps were corrected for a junction potential offset.

\section{Data analysis}

Analysis of in situ hybridization experiments was performed using bright-field microscopy (Olympus BX51, Olympus, Center Valley, PA, USA) and high-resolution digital images were captured under a $4 \times$ objective using an Olympus D570 camera. For fluorescence, digital photographs were obtained from epifluorescence microscopy (Olympus BX61) and selected for further analysis using a Zeiss LSM 510 META confocal microscope (Thornwood, NY, USA). For confocal analysis, each fluorophore was scanned sequentially and confocal images are presented as individual optical sections. Figures were prepared using Adobe Photoshop CS and Adobe Illustrator CS software (Adobe Systems, San Jose, CA, USA). Adjustments to contrast were applied across each image as a whole and equally to control and mutant brains. For anatomical considerations we included the embryonic expression domain terminology of Flames and colleagues
[19]. For the adult anatomy we used the atlas of Franklin and Paxinos [70]. General anatomical consultations were made from prior publications on the posterior MeA $[2,4,33,41]$. All $n$ values for immunohistochemistry, in situ hybridization and electrophysiology are detailed in each corresponding figure legend.

\section{Cell quantification}

To assess the co-expression of immunohistochemical markers in recombined cells from fate-mapping analysis in adults from the three Cre lines, we performed cell counts in the MePD and MePV from two rostro-caudal levels of the posterior MeA, corresponding to Bregma levels $-1.46 \mathrm{~mm}$ and $-1.82 \mathrm{~mm}$. Cells were counted in a $400 \mu \mathrm{m} \times 400 \mu \mathrm{m}$ boxed area through 10 adjacent sections (1- $\mu \mathrm{m}$ steps) of each Z-stack using the LSM510 software. For the fate-mapping analysis we used the Tau ${ }^{m G F P}$ reporter mouse, which was designed with a nuclear localization signal for LacZ [28]. Therefore, we used an anti- $\beta$-gal antibody for nuclear staining of recombined cells, which, along with DAPI counterstaining, facilitated quantification of cells expressing other makers that were also primarily nuclear. The numerical data from the fate-mapping analysis are presented as the average percentage and standard deviation of recombined $\beta$-gal ${ }^{+}$ cells that co-expressed the second marker. Statistical significance was determined using an unpaired $t$-test (alpha value was set at 0.05 ) and was calculated using online GraphPad software (GraphPad Software Inc., La Jolla, CA, USA).

\section{Additional material}

\begin{abstract}
Additional file 1 Expression patterns of excitatory and inhibitory neuronal markers in the MePD and MePV. (A-H) Permanent immunohistochemistry in P22 wild-type brains $(n=3)$ showing the expression of known excitatory and inhibitory neuronal markers in the MePD $(A, C, E, G)$ and MePV $(B, D, F, H)$ of the posterior MeA. $(A, B)$ Tbr1 expression (arrows) is largely devoid in these nuclei, which have primarily a GABAergic neuronal projection output, as indicated by intense GAD65/67 expression (C,D, arrows). (E,H) Interestingly, classic inhibitory markers such as Parvalbumin (E,F, arrows) and Neuropeptide Y (NPY; G,H, arrows) are also sparsely observed in the MePD and MePD. Abbreviations: I, intercalated nuclei of the amygdala; opt, optic tract; sIME, superficial layer of the medial nucleus. Scale bar: $200 \mu \mathrm{m}(\mathrm{A}-\mathrm{H})$

Additional file $\mathbf{2} S h^{C r e}$ recombination in the $R Y F P$ reporter mouse line. (A,B) Permanent immunohistochemistry for GFP in ShhCre; RYFP brains $(n=2)$ shows that this reporter mouse shows the same distribution of Shhlineage cells in the adult MePD ( $A$, arrows) and MePV ( $B$, arrows) as the Tau ${ }^{m G F P}$ reporter line used in this study. Abbreviations: opt, optic tract; sIME, superficial layer of the medial nucleus. Scale bar: $200 \mu \mathrm{m}(\mathrm{A}-\mathrm{H})$.

Additional file 3 Intrinsic electrophysiological properties of Shh-lineage cells in the posterior medial amygdala. Intrinsic electrophysiological properties of Shh-lineage cells in the posterior medial amygdala.
\end{abstract}

\section{Abbreviations}

$\beta$-gal: $\beta$-galactosidase; E: embryonic day; LGE: lateral ganglionic eminence; MeA: medial amygdala; MePD: medial posterodorsal nucleus; MePV: medial posteroventral nucleus; MGE: medial ganglionic eminence; nNOS: neuronal nitric oxide synthase; NS: normal serum; P: postnatal day; PBS: phosphate-buff- 
ered saline; PBST: PBS with Triton 0.03\%; PFA: paraformaldehyde; PPOA: progenitor domain of the preoptic area; POA: preoptic area; RT: room temperature; Shh: Sonic hedgehog; SST: Somatostatin; SW: Swiss-Webster; TM: tamoxifen; YFP. yellow fluorescent protein.

\section{Competing interests}

The authors declare that they have no competing interests.

\section{Authors' contributions}

RSEC and JGC devised the study. RSEC performed all of the experiments with the exception of the electrophysiology, and was the primary contributor to the design, data analysis and figure preparation. J-MM performed the electrophysiology experiments and analysis. KM provided further technical assistance, and along with $\mathrm{LH}, \mathrm{VHS}$ and RPM provided preliminary data. $\mathrm{LH}$ and RPM generated the GliirreER(T2) and Nkx2-1-Cre tissue, respectively. VG, SA and GF provided reagents and gave intellectual input to the study. RSEC wrote the majority of the manuscript with minor contributions from JM-M (electrophysiology methods and results) and JGC. VG, SA and GF further edited and all authors approved the manuscript.

\section{Acknowledgements}

The authors would like to thank Dr Robert Hevner for the Tbr1 antibody. The authors thank Ms Berenice Alfonso for technical assistance at the start of this study. The authors also acknowledge members of the Corbin and Haydar labs in the Center for Neuroscience Research for their helpful discussions.

\section{Author Details}

${ }^{1}$ Center for Neuroscience Research, Children's Research Institute, Children's National Medical Center, Washington, DC 20010, USA, 2Unit on Developmental Neurogenetics, Program in Genomics of Differentiation, Eunice Kennedy Shriver National Institute of Child Health and Human Development, Bethesda, MD 20892, USA, 3Neuroscience Program and Department of Cell Biology, Smilow Research Center, New York University School of Medicine, New York, NY 10016, USA and 4Present address: Molecular Neurobiology Laboratory (MNL-O), The Salk Institute, 10010 North Torrey Pines Road, La Jolla, CA 92037, USA

Received: 8 March 2010 Accepted: 27 May 2010

Published: 27 May 2010

\section{References}

1. Swanson LW, Petrovich GD: What is the amygdala? Trends Neurosci 1998, 21:323-331

2. Garcia-Lopez M, Abellan A, Legaz I, Rubenstein JL, Puelles L, Medina L: Histogenetic compartments of the mouse centromedial and extended amygdala based on gene expression patterns during development. J Comp Neurol 2008, 506:46-74.

3. Hirata T, Li P, Lanuza GM, Cocas LA, Huntsman MM, Corbin JG: Identification of distinct telencephalic progenitor pools for neuronal diversity in the amygdala. Nat Neurosci 2009, 12:141-149.

4. Soma M, Aizawa H, Ito Y, Maekawa M, Osumi N, Nakahira E, Okamoto H, Tanaka K, Yuasa S: Development of the mouse amygdala as revealed by enhanced green fluorescent protein gene transfer by means of in utero electroporation. J Comp Neurol 2009, 513:113-128.

5. $\mathrm{Xu} \mathrm{Q}, \mathrm{Tam} \mathrm{M}$, Anderson SA: Fate mapping Nkx2.1-lineage cells in the mouse telencephalon. J Comp Neurol 2008, 506:16-29.

6. Zhao T, Szabo N, Ma J, Luo L, Zhou X, Alvarez-Bolado G: Genetic mapping of Foxb1-cell lineage shows migration from caudal diencephalon to telencephalon and lateral hypothalamus. Eur J Neurosci 2008 28:1941-1955

7. Carney RS, Alfonso TB, Cohen D, Dai H, Nery S, Stoica B, Slotkin J, Bregman BS, Fishell G, Corbin JG: Cell migration along the lateral cortical stream to the developing basal telencephalic limbic system. J Neurosci 2006, 26:11562-11574.

8. Cocas LA, Miyoshi G, Carney RS, Sousa VH, Hirata T, Jones KR, Fishell G, Huntsman MM, Corbin JG: Emx1-lineage progenitors differentially contribute to neural diversity in the striatum and amygdala. J Neurosci 2009, 29:15933-15946.

9. Remedios R, Huilgol D, Saha B, Hari P, Bhatnagar L, Kowalczyk T, Hevner RF, Suda Y, Aizawa S, Ohshima T, Stoykova A, Tole S: A stream of cells migrating from the caudal telencephalon reveals a link between the amygdala and neocortex. Nat Neurosci 2007, 10:1141-1150.
10. Nery S, Fishell G, Corbin JG: The caudal ganglionic eminence is a source of distinct cortical and subcortical cell populations. Nat Neurosci 2002, 5:1279-1287.

11. Canteras NS: The medial hypothalamic defensive system: hodological organization and functional implications. Pharmacol Biochem Behav 2002, 71:481-491.

12. Choi GB, Dong HW, Murphy AJ, Valenzuela DM, Yancopoulos GD, Swanson LW, Anderson DJ: Lhx6 delineates a pathway mediating innate reproductive behaviors from the amygdala to the hypothalamus. Neuron 2005, 46:647-660.

13. Zirlinger $M$, Kreiman $G$, Anderson DJ: Amygdala-enriched genes identified by microarray technology are restricted to specific amygdaloid subnuclei. Proc Natl Acad Sci USA 2001, 98:5270-5275.

14. Alifragis P, Liapi A, Parnavelas JG: Lhx6 regulates the migration of cortical interneurons from the ventral telencephalon but does not specify their GABA phenotype. J Neurosci 2004, 24:5643-5648.

15. Liodis P, Denaxa M, Grigoriou M, Akufo-Addo C, Yanagawa Y, Pachnis V: Lhx6 activity is required for the normal migration and specification of cortical interneuron subtypes. J Neurosci 2007, 27:3078-3089.

16. Zhao Y, Flandin P, Long JE, Cuesta MD, Westphal H, Rubenstein JL: Distinct molecular pathways for development of telencephalic interneuron subtypes revealed through analysis of Lhx6 mutants. $J$ Comp Neurol 2008, 510:79-99.

17. Du T, Xu Q, Ocbina PJ, Anderson SA: NKX2.1 specifies cortical interneuron fate by activating Lhx6. Development 2008, 135:1559-1567.

18. Sussel L, Marin O, Kimura S, Rubenstein JL: Loss of Nkx2.1 homeobox gene function results in a ventral to dorsal molecular respecification within the basal telencephalon: evidence for a transformation of the pallidum into the striatum. Development 1999, 126:3359-3370.

19. Flames N, Pla R, Gelman DM, Rubenstein JL, Puelles L, Marin O: Delineation of multiple subpallial progenitor domains by the combinatorial expression of transcriptional codes. J Neurosci 2007, 27:9682-9695.

20. Platt KA, Michaud J, Joyner AL: Expression of the mouse Gli and Ptc genes is adjacent to embryonic sources of hedgehog signals suggesting a conservation of pathways between flies and mice. Mech Dev 1997, 62:121-135.

21. Ahn S, Joyner AL: Dynamic changes in the response of cells to positive hedgehog signaling during mouse limb patterning. Cell 2004, 118:505-516.

22. Harfe BD, Scherz PJ, Nissim S, Tian H, McMahon AP, Tabin CJ: Evidence for an expansion-based temporal Shh gradient in specifying vertebrate digit identities. Cell 2004, 118:517-528.

23. Nery S, Wichterle H, Fishell G: Sonic hedgehog contributes to oligodendrocyte specification in the mammalian forebrain. Development 2001, 128:527-540.

24. Bai CB, Auerbach W, Lee JS, Stephen D, Joyner AL: Gli2, but not Gli1, is required for initial Shh signaling and ectopic activation of the Shh pathway. Development 2002, 129:4753-4761.

25. Lee J, Platt KA, Censullo P, Ruiz i Altaba A: Gli1 is a target of Sonic hedgehog that induces ventral neural tube development. Development 1997, 124:2537-2552.

26. Marigo V, Johnson RL, Vortkamp A, Tabin CJ: Sonic hedgehog differentially regulates expression of GLI and GLI3 during limb development. Dev Biol 1996, 180:273-283.

27. Rallu M, Machold R, Gaiano N, Corbin JG, McMahon AP, Fishell G: Dorsoventral patterning is established in the telencephalon of mutants lacking both Gli3 and Hedgehog signaling. Development 2002, 129:4963-4974.

28. Hippenmeyer S, Vrieseling E, Sigrist M, Portmann T, Laengle C, Ladle DR, Arber S: A developmental switch in the response of DRG neurons to ETS transcription factor signaling. PLoS Biol 2005, 3:e159.

29. Flandin $\mathrm{P}$, Kimura $\mathrm{S}$, Rubenstein $\mathrm{J} \mathrm{L}$ : The progenitor zone of the ventral medial ganglionic eminence requires $n k \times 2-1$ to generate most of the globus pallidus but few neocortical interneurons. J Neurosci 2010 30:2812-2823

30. Carney RS, Bystron I, López-Bendito G, Molnár Z: Comparative analysis of extra-ventricular mitoses at early stages of cortical development in rat and human. Brain Struct Funct 2007, 212:37-54

31. Hevner RF, Shi L, Justice N, Hsueh Y, Sheng M, Smiga S, Bulfone A, Goffinet AM, Campagnoni AT, Rubenstein JL: Tbr1 regulates differentiation of the preplate and layer 6. Neuron 2001, 29:353-366. 
32. Markram H, Toledo-Rodriguez M, Wang Y, Gupta A, Silberberg G, Wu C Interneurons of the neocortical inhibitory system. Nat Rev Neurosci 2004, 5:793-807.

33. Guirado S, Real MA, Davila JC: Distinct immunohistochemically defined areas in the medial amygdala in the developing and adult mouse. Brain Res Bull 2008, 75:214-217.

34. Campbell P, Reep RL, Stoll ML, Ophir AG, Phelps SM: Conservation and diversity of Foxp2 expression in muroid rodents: functional implications. J Comp Neurol 2009, 512:84-100.

35. Real MA, Heredia R, Labrador Mdel C, Davila JC, Guirado S: Expression of somatostatin and neuropeptide $Y$ in the embryonic, postnatal, and adult mouse amygdalar complex. J Comp Neurol 2009, 513:335-348.

36. Yu W, Wang Y, McDonnell K, Stephen D, Bai CB: Patterning of ventral telencephalon requires positive function of Gli transcription factors. Dev Biol 2009, 334:264-275.

37. Kimura S, Hara Y, Pineau T, Fernandez-Salguero P, Fox CH, Ward JM, Gonzalez FJ: The T/ebp null mouse: thyroid-specific enhancer-binding protein is essential for the organogenesis of the thyroid, lung, ventral forebrain, and pituitary. Genes Dev 1996, 10:60-69.

38. Marin $\mathrm{O}$, Anderson SA, Rubenstein JL: Origin and molecular specification of striatal interneurons. J Neurosci 2000, 20:6063-6076.

39. Nery S, Corbin JG, Fishell G: Dlx2 progenitor migration in wild type and Nkx2.1 mutant telencephalon. Cereb Cortex 2003, 13:895-903.

40. Corbin JG, Rutlin M, Gaiano N, Fishell G: Combinatorial function of the homeodomain proteins Nkx2.1 and Gsh2 in ventral telencephalic patterning. Development 2003, 130:4895-4906

41. Remedios R, Subramanian L, Tole S: LIM genes parcellate the embryonic amygdala and regulate its development. J Neurosci 2004, 24:6986-6990.

42. Bian X, Yanagawa Y, Chen WR, Luo M: Cortical-like functional organization of the pheromone-processing circuits in the medial amygdala. J Neurophysio/ 2008, 99:77-86.

43. Tanaka M, Ikeda T, Hayashi S, lijima N, Amaya F, Hisa Y, Ibata Y: Nitrergic neurons in the medial amygdala project to the hypothalamic paraventricular nucleus of the rat. Brain Res 1997, 777:13-21.

44. Gorski JA, Talley T, Qiu M, Puelles L, Rubenstein JL, Jones KR: Cortical excitatory neurons and glia, but not GABAergic neurons, are produced in the Emx1-expressing lineage. J Neurosci 2002, 22:6309-6314.

45. Stenman J, Yu RT, Evans RM, Campbell K: TIx and Pax6 co-operate genetically to establish the pallio-subpallial boundary in the embryonic mouse telencephalon. Development 2003, 130:1113-1122.

46. Gelman DM, Martini FJ, Nobrega-Pereira S, Pierani A, Kessaris N, Marin O: The embryonic preoptic area is a novel source of cortical GABAergic interneurons. J Neurosci 2009, 29:9380-9389.

47. Bertrand N, Dahmane N: Sonic hedgehog signaling in forebrain development and its interactions with pathways that modify its effects. Trends Cell Biol 2006, 16:597-605.

48. Hebert JM, Fishell $\mathrm{G}$ : The genetics of early telencephalon patterning: some assembly required. Nat Rev Neurosci 2008, 9:678-685.

49. Rallu M, Corbin JG, Fishell G: Parsing the prosencephalon. Nat Rev Neurosci 2002, 3:943-951.

50. Ruiz i Altaba A, Nguyen V, Palma V: The emergent design of the neural tube: prepattern, SHH morphogen and GLI code. Curr Opin Genet Dev 2003, 13:513-521

51. Ruiz i Altaba A, Palma V, Dahmane N: Hedgehog-Gli signalling and the growth of the brain. Nat Rev Neurosci 2002, 3:24-33.

52. Corbin JG, Gaiano N, Juliano SL, Poluch S, Stancik E, Haydar TF: Regulation of neural progenitor cell development in the nervous system. $J$ Neurochem 2008, 106:2272-2287.

53. Joksimovic M, Anderegg A, Roy A, Campochiaro L, Yun B, Kittappa R, McKay R, Awatramani R: Spatiotemporally separable Shh domains in the midbrain define distinct dopaminergic progenitor pools. Proc Natl Acad Sci USA 2009, 106:19185-19190.

54. Fisher SE, Scharff C: FOXP2 as a molecular window into speech and language. Trends Genet 2009, 25:166-177.

55. Vernes SC, Newbury DF, Abrahams BS, Winchester L, Nicod J, Groszer M, Alarcón M, Oliver PL, Davies KE, Geschwind DH, Monaco AP, Fisher SE: A functional genetic link between distinct developmental language disorders. NEngl J Med 2008, 359:2337-2345

56. Lu S, Shashikant CS, Ruddle FH: Separate cis-acting elements determine the expression of mouse $\mathrm{Dbx}$ gene in multiple spatial domains of the central nervous system. Mech Dev 1996, 58:193-202.
57. Shoji H, Ito T, Wakamatsu Y, Hayasaka N, Ohsaki K, Oyanagi M, Kominami $\mathrm{R}$, Kondoh $\mathrm{H}$, Takahashi $\mathrm{N}$ : Regionalized expression of the Dbx family homeobox genes in the embryonic CNS of the mouse. Mech Dev 1996, 56:25-39.

58. Fogarty M, Grist M, Gelman D, Marin O, Pachnis V, Kessaris N: Spatial genetic patterning of the embryonic neuroepithelium generates GABAergic interneuron diversity in the adult cortex. J Neurosci 2007, 27:10935-10946.

59. Nobrega-Pereira S, Gelman D, Bartolini G, Pla R, Pierani A, Marin O: Origin and molecular specification of globus pallidus neurons. J Neurosci 2010, 30:2824-2834

60. Butt SJ, Sousa VH, Fuccillo MV, Hjerling-Leffler J, Miyoshi G, Kimura S, Fishell G: The requirement of Nkx2-1 in the temporal specification of cortical interneuron subtypes. Neuron 2008, 59:722-732.

61. $\mathrm{Xu} Q \mathrm{Q}$, Wonders $\mathrm{CP}$, Anderson SA: Sonic hedgehog maintains the identity of cortical interneuron progenitors in the ventral telencephalon. Development 2005, 132:4987-4998.

62. Methot N, Basler K: An absolute requirement for Cubitus interruptus in Hedgehog signaling. Development 2001, 128:733-742.

63. Dai P. Akimaru H, Tanaka Y, Maekawa T, Nakafuku M, Ishii S: Sonic Hedgehog-induced activation of the Gli1 promoter is mediated by GLI3. J Biol Chem 1999, 274:8143-8152.

64. Park HL, Bai C, Platt KA, Matise MP, Beeghly A, Hui CC, Nakashima M, Joyner AL: Mouse Gli1 mutants are viable but have defects in $\mathrm{SHH}$ signaling in combination with a Gli2 mutation. Development 2000 127:1593-1605.

65. Sasaki H, Hui C, Nakafuku M, Kondoh H: A binding site for Gli proteins is essential for HNF-3beta floor plate enhancer activity in transgenics and can respond to Shh in vitro. Development 1997, 124:1313-1322.

66. Usunoff KG, Schmitt O, Itzev DE, Haas SJ, Lazarov NE, Rolfs A, Wree A: Efferent projections of the anterior and posterodorsal regions of the medial nucleus of the amygdala in the mouse. Cells Tissues Organs 2009, 190:256-285.

67. Srinivas S, Watanabe T, Lin CS, William CM, Tanabe Y, Jessell TM, Costantini $\mathrm{F}$ : Cre reporter strains produced by targeted insertion of EYFP and ECFP into the ROSA26 locus. BMC Dev Biol 2001, 1:4

68. Carney RS, Cocas LA, Hirata T, Mansfield K, Corbin JG: Differential regulation of telencephalic pallial-subpallial boundary patterning by pax6 and gsh2. Cereb Cortex 2009, 19:745-759.

69. Raineteau O, Hugel S, Ozen I, Rietschin L, Sigrist M, Arber S, Gahwiler BH: Conditional labeling of newborn granule cells to visualize their integration into established circuits in hippocampal slice cultures. Mol Cell Neurosci 2006, 32:344-355

70. Franklin KBJ, Paxinos G: The Mouse Brain In Stereotaxic Coordinates 3rd edition. New York: Elsevier; 2008

doi: $10.1186 / 1749-8104-5-14$

Cite this article as: Carney et al., Sonic hedgehog expressing and responding cells generate neuronal diversity in the medial amygdala Neural Development 2010, 5:14

\section{Submit your next manuscript to BioMed Centra and take full advantage of:}

- Convenient online submission

- Thorough peer review

- No space constraints or color figure charges

- Immediate publication on acceptance

- Inclusion in PubMed, CAS, Scopus and Google Scholar

- Research which is freely available for redistribution 